\title{
Desenvolvimento da alface Elisa em diferentes sistemas de irrigação com água residuária ${ }^{1}$
}

\author{
Delvio Sandri ${ }^{2}$, Edson E. Matsura ${ }^{3}$ \& Roberto Testezlaf ${ }^{3}$
}

\begin{abstract}
RESUMO
Neste trabalho, teve-se como objetivo principal avaliar o uso de água residuária e água de um reservatório superficial, no desenvolvimento da alface (Lactuca sativa L.), cv "Elisa", durante dois ciclos de cultivo. Analisou-se o desenvolvimento da cultura aos 13, 25, 33, 40 e 45 dias após o transplantio no $1^{\circ}$ ciclo e aos 14, 25, 33, 41 e 47 dias, no $2^{\circ}$ ciclo, determinando-se a classificação comercial e eficiência do uso de água, ao final de cada ciclo, comparando-se os sistemas de irrigação por aspersão, gotejamento subterrâneo e superficial, concluindo-se que: os maiores valores de massa seca, massa fresca e área foliar, foram obtidos nos tratamentos com água residuária, enquanto a altura da planta e o número de folhas foram pouco influenciados pelo tipo de água. A produtividade nos dois ciclos foi mais elevada nos sistemas de irrigação por gotejamento subterrâneo, seguido pelo superficial, utilizando-se água residuária. A maior eficiência no uso de água foi obtida nos sistemas de irrigação por gotejamento, em que se usou água residuária em ambos os ciclos da cultura; por outro lado, as plantas, em sua maior porcentagem, nas quais se empregou água residuária e do reservatório, apresentavam-se nas classes 20 e 25 e 15 e 20, respectivamente, em ambos os ciclos da cultura. Enfim, os melhores resultados no desenvolvimento, classificação comercial e eficiência de água, foram obtidos com água residuária aplicada pelos sistemas de irrigação por gotejamento.
\end{abstract}

Palavras-chave: reúso, aspersão, classificação comercial, eficiência do uso de água, Lactuca sativa L.

\section{Development of the lettuce Elisa in different irrigation systems with wastewater}

\begin{abstract}
The main scope of this study was to compare the use of wastewater and surface reservoir water on the development of the lettuce (Lactuca sativa L.), cv "Elisa", during two crop cycles. The crop development was analyzed at the 13, 25, 33, 40 and 45 days after the transplanting in the $1^{\text {st }}$ cycle and at the $14,25,33,41$ and 47 days in the $2^{\text {nd }}$ cycle. The commercial classification and water use efficiency at the end of each cycle was evaluated, comparing the sprinkler, subsurface and surface drip irrigation systems. The highest value of dry mass, fresh mass and leaf area were found for the treated wastewater, although the plant height and the leaf number were not affected by its use and the yield in the two cycles was higher for the subsurface drip irrigation treatment, followed by the surface drip using wastewater. The highest value of the water use efficiency was obtained in the drip irrigation systems, using wastewater in both crop cycles; on the other hand, the largest percentage of plants, under wastewater or surface reservoir water treatments, were classified in classes 20 and 25 and 15 and 20, respectively, in both crop cycles. The best results for the crop development, commercial classification and water use efficiency were obtained for wastewater applied through drip irrigation systems.
\end{abstract}

Key words: reuse, sprinkler, commercial classification, water use efficiency, Lactuca sativa L.

1 Parte da Tese de Doutorado do primeiro autor. Pesquisa financiada pela FAPESP

2 Eng. Agrícola/UEG, BR 153, KM 98, CP 459, CEP 75110-390, Anápolis, GO. Fone: (62) 3328-1160. E-mail: sandri@ueg.br.

${ }^{3}$ FEAGRI/UNICAMP, CP 1160, CEP 13083-970, Campinas, SP. E-mail: matsura@agr.unicamp.br. Fone: (19) 3788-1023. E-mail: bob@agr.unicamp.br. Fone: (19) 3788-1024 


\section{INTRODUÇÃO}

A utilização da água residuária tratada na agricultura pode ser importante não apenas como fonte extra de água, mas também devido a vários outros fatores, como: servir de fonte de nutrientes, visto que podem auxiliar no desenvolvimento da cultura. De acordo com Friedler \& Juniaco (1996), a aplicação dos nutrientes contidos nos esgotos ou efluentes tratados pode reduzir, ou mesmo eliminar, a necessidade de fertilizantes comerciais.

Estudos conduzidos por Osburn \& Burkhead (1992) para avaliar a possibilidade do uso de efluentes com tratamento secundário utilizando a irrigação por gotejamento e a aspersão, nas culturas do pepino e berinjela, mostraram que a qualidade da água influenciou no aumento da massa verde das plantas mas não a produtividade, ao contrário de outros estudos, que indicaram aumento da produtividade quando do uso de efluente secundário (Jucken, 2000; Biscaro et al., 2002).

Apenas avaliar a produção final de uma cultura não é suficiente no estudo da interação planta-ambiente e de seu desenvolvimento, razão por que são necessárias observações mais detalhadas quanto ao comportamento do crescimento. Hunt (1978) observou que a análise de crescimento de plantas cultivadas em condições naturais e controladas, permite a obtenção de informações comparativas importantes. Para uma cultura como a alface, a área foliar é uma medida essencial na determinação do desenvolvimento da planta, pois é mais interessante que a alface tenha maior área foliar total que um número maior de folhas ou uma boa altura. A maior área foliar resulta em maior material produzido no processo de fotossíntese; além disso, conforme observado por Hamada (1995), a massa fresca total é influenciada principalmente pela área foliar, sendo que a área foliar de uma planta depende do número e do tamanho das folhas e, por conseqüência, do estádio de desenvolvimento. As medidas de altura e número de folhas também são significativos visto que servem como dados comparativos. Em análise de crescimento toma-se como base a massa seca, como representativa da fitomassa produzida, o que se faz necessário, visto que o teor de água na planta varia com a hora do dia, condições ambientais, estádio de desenvolvimento da planta, tempo entre a colheita e a medição, entre outros; por outro lado, cerca de 90\%, em média, da matéria seca acumulada, resultam da atividade fotossintética (Pereira \& Machado, 1987).

De acordo com a variedade, a alface pode ser classificada nos grupos crespa, lisa, mimosa, romana e americana e subgrupo em verde e roxa; devido às suas características intrínsecas, os diferentes grupos diferem quanto aos fatores: época de colheita, tamanho, compactação e coloração da cabeça, espessura de folhas, resistência a doenças e comportamento fisiológico (Camargo, 1984; CEAGESP, 2001).

Nas propriedades localizadas no “cinturão verde” do município de Campinas, SP, e outros grandes centros urbanos do Brasil, são cultivadas várias hortaliças, a maioria de ciclo curto, sendo a alface a que apresenta maior importância econômica, de vez que compreende a hortaliça folhosa de maior produção e consumo, de destacada importância nutricional, encontrando-se presente regularmente no cardápio da população brasileira. Segundo a CEASA (2006) no Estado de São Paulo o consumo "per capita” foi estimado em cerca de $2 \mathrm{~kg}$ ao ano, sendo que $40 \%$ dos seus gastos totais com verduras são destinados à compra da alface, a qual, devido à sua alta perecibilidade procede em geral, de áreas localizadas nas proximidades de grandes centros urbanos, como a cidade de São Paulo. Apesar de serem muitos os municípios que compõem o cinturão verde, poucos produzem esta hortaliça para o abastecimento da capital paulista (Silva et al., 2006). A produção de alface no estado de São Paulo ocupa aproximadamente uma área de 7.859 ha, produzindo 137 mil toneladas por ano, gerando mais de 6.000 empregos. Os principais municípios fornecedores são Piedade (18\%), Mogi das Cruzes (14\%) e Suzano (11\%) (CEASA, 2006).

Com este trabalho, objetivou-se avaliar o efeito da aplicação de água residuária tratada com macrófitas e água de um reservatório de fonte hídrica superficial, no desenvolvimento, classificação comercial e eficiência do uso da água na alface (Lactuca sativa L.), cv "Elisa”, durante dois ciclos, através dos sistemas de irrigação por aspersão, gotejamento subterrâneo e superficial.

\section{MATERIAL E MÉTODOS}

O estudo foi desenvolvido no Campo Experimental da Faculdade de Engenharia Agrícola da Universidade Estadual de Campinas (FEAGRI/UNICAMP), localizado na Cidade Universitária “Zeferino Vaz”, distrito de Barão Geraldo, Campinas, SP, com Latitude de $22^{\circ} 53^{\prime}$ S e Longitude de $47^{\circ} 05^{\prime}$ W. O solo foi classificado como Latossolo Vermelho distroférrico. O clima, segundo a classificação de Köppen, é uma transição entre Cwa e Cwf, isto é, subtropical de altitude, seco no inverno e chuvoso e quente no verão, com precipitação média anual em torno de $1370 \mathrm{~mm}$, temperatura média anual de $21,7^{\circ} \mathrm{C}$ e umidade relativa do ar de $66,2 \%$. As condições térmicas e de umidade relativa do ar nos períodos experimentais, encontram-se descritas na Tabela 1.

Tabela 1. Temperaturas (T) médias, mínimas e máximas mensais e umidade relativa do ar (UR) durante os períodos experimentais dos $1^{\circ}$ e $2^{\circ}$ ciclos

\begin{tabular}{ccccc}
\hline \multirow{2}{*}{ Ciclos } & \multicolumn{3}{c}{ Temperaturas $\left({ }^{\circ} \mathrm{C}\right)$} & \multirow{2}{*}{ UR $(\%)$} \\
\cline { 2 - 3 } $1^{0}(08 / 06$ a $23 / 07 / 01)$ & T média & T máx. média T mín. média & \\
$2^{\circ}(17 / 08$ a 03/10/01) & 21,0 & 25,0 & 12,6 & 70,5 \\
\hline
\end{tabular}

Fonte: Estação climática da FEAGRI/UNICAMP, Campinas, SP

Durante o $2^{\circ}$ ciclo ocorreu uma precipitação de $197,0 \mathrm{~mm}$, concentrada principalmente no final do ciclo; em apenas dois dias choveu $100,8 \mathrm{~mm}$ (51\% do total do período); por outro lado, no $1^{\circ}$ ciclo, choveu apenas $33,9 \mathrm{~mm}$, de cujo total 14,9 mm (44\%) ocorreram em um único dia (26/06/2001).

O delineamento experimental compreendeu um esquema fatorial, com três sistemas de irrigação (aspersão, gotejamento subterrâneo e superficial) x duas qualidades de água (água residuária tratada e água do depósito superficial), com três 
repetições. Os tratamentos utilizados foram: AR: aspersão, utilizando água residuária; AD: aspersão, utilizando-se água do depósito; GSbR: gotejamento subterrâneo com água residuária; GSbD: gotejamento subterrâneo mais água do depósito; GSpR: gotejamento superficial e água residuária, e GSpD: gotejamento superficial utilizando-se água do depósito.

A água utilizada no tratamento testemunha foi captada de um reservatório existente na própria Faculdade de Engenharia Agrícola, abastecido por bombeamento, de um reservatório a céu aberto. A Faculdade de Engenharia Agrícola é servida pela Companhia de Abastecimento de Água de Campinas (SANASA) e por poços artesianos localizados no campus universitário.

O esgoto, retirado da rede local, se compunha de uma mistura de dejetos sanitários de diversas edificações: laboratórios de ensino e pesquisa (armazenamento e pré-processamento de produtos agrícolas, construções rurais e máquinas agrícolas), prédios de sala de aula e administração, cozinha, cantina e oficina mecânica: era descartado na rede coletora, praticamente todo o resíduo oriundo das atividades destes locais, porém, sua composição era prioritariamente advinda da higiene humana, tendo pouca ou nenhuma contribuição de produtos químicos das atividades laboratoriais.

O efluente foi tratado por um reator anaeróbio compartimentado composto de três caixas de cimento amianto em série de 1.000, 500 e 500 L, passando, em seguida, por seis leitos com brita de área igual a $4 \mathrm{~m}^{2}$, três dos quais de formato retangular ( 4 x $1 \mathrm{~m}$ ) e três quadrados ( 2 x 2 m), dispostos em paralelo. O meio de suporte foi a brita \# 2 com diâmetro equivalente de 55 a $90 \mathrm{~mm}$ e $50 \%$ de porosidade, cultivados com macrófitas enraizadas e emergentes Typha sp. (taboa) e Eleocharis sp. (junco manso), com vazão subsuperficial. O tempo de retenção hidráulica foi de cerca de 5 dias, volume útil calculado de $1,2 \mathrm{~m}^{3}$, declividade do leito de $1 \%$ e profundidade de $0,7 \mathrm{~m}$, altura da coluna d'água variável até $0,6 \mathrm{~m}$. A eficiência do sistema de tratamento do efluente foi estudado por Valentim (2003), onde são apresentados os resultados; neste trabalho, apenas foi realizado o reúso, em que após o tratamento, o efluente era armazenado em um reservatório com capacidade para 15.000 L e, posteriormente, utilizado na irrigação.

As coletas da água residuária e do depósito de fonte hídrica superficial para análise química e para determinação dos coliformes totais (CT) e E. coli (EC), foram realizadas aos 10, 25 e 45 dias após o transplantio (DAT) das mudas de alface para o campo; as amostras de água para as análises foram retiradas na saída do bocal dos aspersores e, após o sistema de filtragem composto de filtro de areia e tela de 125 microns (120 mesh) na irrigação por gotejamento subterrâneo e superficial, analisada separadamente e em seguida efetuada a média aritmética; as amostras de água foram acondicionadas em garrafas de vidro transparente esterilizadas, próprias para coleta, com volume total de $250 \mathrm{~mL}$ e posteriormente armazenadas a $4{ }^{\circ} \mathrm{C}$, conforme indicado por APHA (1995).

Os parâmetros analisados na água residuária e do depósito superficial foram o sódio ( $\mathrm{Na})$, cálcio (Ca), magnésio $(\mathrm{Mg})$, manganês $(\mathrm{Mn})$, enxofre $(\mathrm{S})$, ferro $(\mathrm{Fe})$, boro $(\mathrm{B})$, potássio (K), fósforo ( $\mathrm{P}$ e $\left.\mathrm{P}_{2} \mathrm{O}_{5}\right)$, nitrogênio amônio ( $\mathrm{N}$ $\mathrm{NH}_{4}{ }^{+}$) e nitrogênio nitrato $\left(\mathrm{N}-\mathrm{NO}_{3}{ }^{-}\right)$, demanda bioquímica de oxigênio (DBO), conforme descrito em APHA (1995) e Hach (1997) e calculando-se a razão de absorção de sódio (RAS) e os sólidos dissolvidos totais (SDT). A condutividade elétrica (EC) foi determinada com um condutivímetro, marca Digimed DM 31 e o pH com um peagâmetro de bancada, Orion (eletrodo de platina imerso em solução eletrolítica), pelo método eletrométrico, segundo APHA (1995). A presença de coliformes totais (CT) e E. coli (EC) na água de irrigação foi analisada pelo método do substrato definido, conhecido comercialmente como Colilert-IDEXX, utilizando-se a cartela QuantiTray, seladora Quanti-Sealer e lâmpada UV, cujo resultados foram obtidos após 24 horas de incubação em estufa biológica a $35^{\circ} \mathrm{C}$. Os materiais necessários e procedimentos estão descritos no APHA (1995).

Para cada sistema de irrigação foram construídos 3 canteiros, com 1,20 m de largura, 10,0 m de comprimento e 0,2 m de altura, utilizados durante os dois ciclos da cultura. No gotejamento subterrâneo e superficial, instalaram-se duas linhas de gotejadores CarboDrip tipo labirinto por canteiro, sendo que, no gotejamento subterrâneo, as mesmas foram enterradas a uma profundidade de $0,10 \mathrm{~m}$. O espaçamento entre emissores na linha lateral era de $0,40 \mathrm{~m}$ e vazão nominal de 2,3 $\mathrm{L} \mathrm{h}^{-1}$, enquanto no tratamento por aspersão, se instalaram quatro aspersores setoriais, marca Naan, modelo 5022, com vazão individual de $0,45 \mathrm{~m}^{3} \mathrm{~h}^{-1}$, espaçados 12,0 x 12,0 m.

No momento da confecção dos canteiros foram incorporados, na camada de $0-0,2 \mathrm{~m}$, tanto no $1^{\circ}$ como no $2^{\circ}$ ciclos, $33 \mathrm{~kg} \mathrm{ha}^{-1}$ de $\mathrm{N}, 116 \mathrm{~kg} \mathrm{ha}^{-1}$ de $\mathrm{P}_{2} \mathrm{O}_{5}$ e $67 \mathrm{~kg} \mathrm{ha}^{-1}$ de $\mathrm{K}_{2} \mathrm{O}$, considerando-se a recomendação de Trani \& van Raij (1997) e mais 20,8 t ha-1 de um condicionador de solo à base de turfa, o qual apresenta alto teor de matéria orgânica, contendo nitrogênio e magnésio em sua composição e apresentando condutividade elétrica (1:2 base volume) entre 0,5 e $1,3 \mathrm{dS} \mathrm{m}^{-1}$ e pH entre 5,5 e 6,2. Em cobertura foram aplicados, por vez, $150 \mathrm{~kg} \mathrm{ha}^{-1}$ de $\mathrm{N}$ na forma de sulfato de amônio (com 20\% de $\mathrm{N}$ ), aos 20 e 32 dias após o transplantio (DAT) no $1^{\circ}$ ciclo e aos 10, 20 e 32 DAT no $2^{\circ}$ ciclo. Como cobertura morta utilizou-se 1 a $2 \mathrm{~cm}$ de bagaço de cana-deaçúcar moído.

As características químicas do solo do local do experimento antes do início da irrigação com água residuária e nos finais dos $1^{\circ}$ e $2^{\circ}$ ciclos, são apresentadas na Tabela 2. O local de coleta das amostras de solo no canteiro foi sempre o mesmo, ou seja, entre duas plantas de alface em uma das linhas de plantas dentro da área útil.

O espaçamento entre as plantas foi de 0,25 x 0,25 m (16 plantas por $\mathrm{m}^{2}$ ), no total de quatro linhas de planta por canteiro (Lisbão et al., 1990). A aplicação da água para a cultura foi realizada diariamente, às 17:30 h, e a lâmina determinada a partir da evapotranspiração de referência do dia anterior, obtida pela equação de Penman Monteith, fornecida por uma estação climática automática, instalada a aproximadamente $150 \mathrm{~m}$ do local do experimento, considerando-se o valor do coeficiente de cultura $\left(\mathrm{K}_{\mathrm{c}}\right)$ igual a 0,6 entre o $8^{\circ}$ e o $24^{\circ}$ DAT e 1,0 do período até o final do ciclo. 
Tabela 2. Valores médios das características* do solo do local do experimento antes do inicio da irrigação com água residuária e nos finais dos $1^{\circ}$ e $2^{\circ}$ ciclos

\begin{tabular}{|c|c|c|c|c|c|c|c|c|c|c|c|c|c|}
\hline \multirow{2}{*}{$\begin{array}{c}\mathrm{pH} \\
\mathrm{CaCl}_{2}\end{array}$} & $P$ & $S$ & K & $\mathrm{Na}$ & $\mathrm{Ca}$ & $\mathrm{Mg}$ & Al & $\mathrm{H}+\mathrm{Al}$ & SB & CTC & MO & V & \multirow{2}{*}{$\begin{array}{c}\text { EC } \\
\text { dS } \mathrm{m}^{-1}\end{array}$} \\
\hline & \multicolumn{2}{|c|}{$\mathrm{mg} \mathrm{dm}^{-3}$} & \multicolumn{7}{|c|}{$\mathrm{mmol}_{\mathrm{c}} \mathrm{dm}^{-3}$} & & \multicolumn{2}{|c|}{$\%$} & \\
\hline \multicolumn{14}{|c|}{ Antes do início da irrigacão com áqua residuária } \\
\hline 5,8 & 46,9 & 18,7 & 0,40 & 6,7 & 4,4 & 1,3 & * & 2,9 & 6,3 & 9,2 & 3,3 & 68,3 & 0,22 \\
\hline \multicolumn{14}{|c|}{ Final do $1^{0}$ ciclo } \\
\hline 5,5 & 47,8 & 17,7 & 0,39 & 14,3 & 4,4 & 1,3 & * & 3,3 & 6,1 & 9,4 & 3,8 & 65,1 & 0,21 \\
\hline \multicolumn{14}{|c|}{ Final do $2^{0}$ ciclo } \\
\hline 5,3 & 54,2 & 30,0 & 0,27 & 11,3 & 4,5 & 1,7 & * & 3,3 & 6,5 & 9,8 & 4,5 & 65,9 & 0,23 \\
\hline
\end{tabular}

* Abaixo do limite de detecção, Fósforo (P); Enxofre (S); Potássio (K); Sódio (Na); Cálcio (Ca); Magnésio (Mg); Alumínio (Al); Hidrogênio (H); Soma de bases (SB); Capacidade de troca de cátions (CTC); Matéria orgânica (M0); Saturação de Bases (V) e Condutividade elétrica (EC)

Em razão das precipitações ocorridas no período experimental, as lâminas de água aplicadas acumuladas totalizaram, para o $1^{\circ}$ ciclo: $72,1,73,0,74,7,75,8,79,5$ e $80,6 \mathrm{~mm}$ e, para o $2^{\circ}$ ciclo, de 127,2, 127,9, 131,2, 134,5, 142,7 e 143,2 mm, para os tratamentos GSpR, GSpD, GSbD, GSbR, AR e AD, respectivamente.

Para avaliação dos dados fenométricos realizaram-se colheitas manuais da alface durante o período de crescimento para os dois ciclos da cultura, ou seja, aos 13, 25, 33, 40 e 45 DAT no $1^{\circ}$ ciclo, compreendido no período de 08/06 a 23/ 07/2001 e aos 14, 25, 33, 41 e 47 DAT no $2^{\circ}$ ciclo, realizado no período de 17/08 a 03/10/2001. Os parâmetros de crescimento analisados foram: altura, número de folhas, área foliar, massa seca e massa fresca.

Determinou-se a altura das plantas com auxílio de uma régua graduada, com precisão de $1 \mathrm{~mm}$, medida a partir da base da planta até a altura máxima das folhas. A massa fresca foi determinada em balança analítica, com precisão de 0,001 g, logo após a coleta das plantas em campo. Para a determinação do número de folhas e área foliar, consideramse apenas as folhas com altura igual ou superior a $1,0 \mathrm{~cm}$. Para medição da área foliar utilizou-se um equipamento eletrônico, integrador de área portátil, Marca LICOR, Modelo LI-3000 A, com precisão de $0,01 \mathrm{~cm}^{2}$. Após as medições, as plantas foram acondicionadas em sacos de papel abertos e furados e colocadas para secar em estufa de ar forçado a $60{ }^{\circ} \mathrm{C}$, durante 72 horas ou até atingir massa constante para, então, determinar a matéria seca.

A avaliação da produção e classificação comercial foi realizada somente no final de cada um dos dois ciclos, sendo amostradas, aleatoriamente, três plantas em cada uma das cinco subparcelas em que cada canteiro foi dividido.

Alternativamente, a classificação tradicional com engradados, a CEAGESP (Companhia de Entrepostos e Armazéns Gerais de São Paulo) e a Secretaria da Agricultura e Abastecimento do Estado de São Paulo, sugerem uma proposta de participação voluntária para a classificação da alface, dentro do programa paulista, para melhoria dos padrões comerciais e embalagens de hortigranjeiros com o objetivo de definir as características de identidade, qualidade, embalagem, acondicionamento e apresentação da alface destinada ao consumo "in natura", no mercado atacadista interno. A Tabela 3 apresenta a classificação da alface segundo o peso da massa fresca proposto pela CEAGESP (2001).

Os dados foram submetidos a análise de variância e comparação de média, aplicando-se o teste de Tukey a 5\% de proba-
Tabela 3. Classificação da alface segundo a massa fresca sugerida pela CEAGESP (2001)

\begin{tabular}{ccccccc}
\hline \multicolumn{3}{c}{ Limite de peso } & & \multicolumn{3}{c}{ Limite de peso } \\
\cline { 1 - 3 } \cline { 5 - 7 } inferior $(\mathbf{g})$ & Classe & superior $(\mathbf{g})$ & & inferior $(\mathbf{g})$ & Classe & superior $(\mathbf{g})$ \\
Sem limite & 5 & $<100$ & & $\leq 550$ & 55 & $<600$ \\
$\geq 100$ & 10 & $<150$ & & $\leq 600$ & 60 & $<650$ \\
$\geq 150$ & 15 & $<200$ & & $\leq 650$ & 65 & $<700$ \\
$\geq 200$ & 20 & $<250$ & & $\leq 700$ & 70 & $<750$ \\
$\geq 250$ & 25 & $<300$ & & $\leq 750$ & 75 & $<800$ \\
$\geq 300$ & 30 & $<350$ & & $\leq 800$ & 80 & $<850$ \\
$\geq 350$ & 35 & $<400$ & & $\leq 850$ & 85 & $<900$ \\
$\geq 400$ & 40 & $<450$ & & $\leq 900$ & 90 & $<950$ \\
$\geq 450$ & 45 & $<500$ & & $\leq 950$ & 95 & $<1000$ \\
$\geq 500$ & 50 & $<550$ & & $\leq 1000$ & 100 & sem limite \\
\hline
\end{tabular}

OBS: É tolerada uma mistura de $10 \%$ de pés de alface de classes diferentes da especificada no rótulo, desde que pertencentes às classes imediatamente superiores e/ou inferiores

bilidade de erro, utilizando-se o Software ESTAT - Sistema de Análises Estatísticas, desenvolvido na UNESP, Jaboticabal.

\section{RESULTADOS E DISCUSSÃO}

\section{Qualidade da água}

A Tabela 4 apresenta os valores médios da qualidade da água residuária tratada e da água do depósito, aos 10, 25 e 45 DAT, utilizadas na irrigação por aspersão, gotejamento subterrâneo e superficial, nos $1^{\circ}$ e $2^{\circ}$ ciclos.

Observou-se que, em todas as amostras de água residuária tratada, as concentrações de Escherichia coli ficaram acima do limite permitido pela WHO (1989) para irrigação irrestrita, e por Brasil (2005), que não permitem ultrapassar o limite de 1000 Escherichia coli por $100 \mathrm{~mL}$ de água, para a irrigação de vegetais consumidos crus. Quanto à concentração dos coliformes totais, os índices observados, segundo Trani (2001), são maiores que o máximo permitido para aplicação na irrigação, visto que não devem ultrapassar de 5000 coliformes totais por $100 \mathrm{~mL}$ de água.

Barros et al. (1999) avaliaram a qualidade sanitária e físico-química das águas utilizadas na irrigação de hortaliças em cinco hortas localizadas em dois municípios paraibanos, observando elevada contaminação fecal (CF: 104 UFC $100 \mathrm{~mL}^{-1}$ ) contaminando os vegetais, tendo como origem as descargas de esgotos domésticos nos córregos e açudes, cujas águas são utilizadas na irrigação, resultando no reúso indireto de esgotos na agricultura. 
Tabela 4. Qualidade da água residuária tratada e da água do depósito, analisadas aos 10, 25 e 45 dias após o transplantio da alface em campo

\begin{tabular}{|c|c|c|c|c|c|c|}
\hline \multirow{3}{*}{$\begin{array}{l}\text { Tipo de água } \\
\text { Parâmetros }\end{array}$} & \multicolumn{3}{|c|}{ Água residuária } & \multicolumn{3}{|c|}{ Água do depósito } \\
\hline & \multicolumn{3}{|c|}{ Dias após o transplantio } & \multicolumn{3}{|c|}{ Dias após o transplantio } \\
\hline & 10 & 25 & 45 & 10 & 25 & 45 \\
\hline CT (NMP $100 \mathrm{~mL}^{-1}$ ) & $6,2 \times 10^{5}$ & $1,1 \times 10^{5}$ & $1,1 \times 10^{5}$ & $6,2 \times 10^{4}$ & $1,1 \times 10^{3}$ & $1,8 \times 10^{4}$ \\
\hline EC (NMP $\left.100 \mathrm{~mL}^{-1}\right)$ & $1,2 \times 10^{5}$ & $1,7 \times 10^{4}$ & $3,6 \times 10^{4}$ & 36 & 31 & 3 \\
\hline $\mathrm{N}-\mathrm{NH}_{4}^{+}\left(\mathrm{mg} \mathrm{L}^{-1}\right)$ & 36,1 & 32,5 & 37,4 & 0,0 & 0,0 & 0,0 \\
\hline $\mathrm{N}-\mathrm{NO}_{3}^{-}\left(\mathrm{mg} \mathrm{L}^{-1}\right)$ & 0,8 & 1,2 & 0,3 & 0,3 & 0,4 & 0,2 \\
\hline$P\left(\mathrm{mg} \mathrm{L}^{-1}\right)$ & 1,55 & 2,35 & 1,45 & 0,12 & 0,02 & 0,13 \\
\hline $\mathrm{P}_{2} \mathrm{O}_{5}\left(\mathrm{mg} \mathrm{L}^{-1}\right)$ & 3,41 & 5,35 & 1,83 & 0,27 & 0,05 & 0,32 \\
\hline $\mathrm{K}\left(\mathrm{mmol}_{\mathrm{C}} \mathrm{L}^{-1}\right)$ & 0,23 & 0,28 & 0,31 & 0,01 & 0,01 & 0,03 \\
\hline $\mathrm{Ca}\left(\mathrm{mmol}_{\mathrm{c}} \mathrm{L}^{-1}\right)$ & 1,42 & 1,50 & 1,53 & 0,23 & 0,18 & 0,20 \\
\hline $\mathrm{Na}\left(\mathrm{mmol}_{\mathrm{c}} \mathrm{L}^{-1}\right)$ & 0,78 & 0,84 & 0,80 & 0,09 & 0,09 & 0,04 \\
\hline $\mathrm{Mg}\left(\mathrm{mmol}_{\mathrm{c}} \mathrm{L}^{-1}\right)$ & 0,21 & 0,16 & 0,25 & 0,17 & 0,17 & 0,17 \\
\hline RAS $\left(\mathrm{mmol} \mathrm{L}^{-1}\right)^{1 / 2}$ & 0,86 & 0,92 & 0,85 & 0,20 & 0,21 & 0,10 \\
\hline $\mathrm{CE}\left(\mathrm{dS} \mathrm{m}^{-1}\right)$ & 0,52 & 0,52 & 0,63 & 0,06 & 0,05 & 0,05 \\
\hline $\mathrm{pH}$ & 7,2 & 7,4 & 7,4 & 6,9 & 7,1 & 6,9 \\
\hline$S\left(\mathrm{mg} \mathrm{L}^{-1}\right)$ & 2,5 & 3,0 & 4,0 & 1,0 & 1,0 & 2,5 \\
\hline $\mathrm{DB} 0\left(\mathrm{mg} \mathrm{L}^{-1}\right)$ & 23 & 53 & 5 & 15 & 40 & 0 \\
\hline$B\left(m g L^{-1}\right)$ & * & 0,1 & 0,1 & * & * & 0,3 \\
\hline $\mathrm{Fe}\left(\mathrm{mg} \mathrm{L}^{-1}\right)$ & 1,1 & 0,8 & 0,5 & 0,4 & 0,9 & 0,9 \\
\hline$M n\left(m g ~ L^{-1}\right)$ & * & * & * & * & * & * \\
\hline $\mathrm{SDT}^{1}\left(\mathrm{mg} \mathrm{L}^{-1}\right)$ & 332,8 & 332,8 & 403,2 & 38,4 & 32,0 & 32,0 \\
\hline
\end{tabular}

* Abaixo do limite de detecção; RAS = Razão de Absorção de Sódio; SDT = Sólidos Dissolvidos Totais; CE = Condutividade Elétrica; CT = Coliformes totais; EC = Escherichia coli

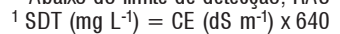

O sistema de tratamento utilizado (reatores anaeróbico compartimentados seguidos de leitos cultivados com macrófitas), não foi eficaz na remoção dos coliformes totais e Escherichia coli, a níveis abaixo dos exigidos para aplicação na irrigação de culturas consumidas cruas, o que se sugere aumentar o tempo de retenção hidráulica do sistema de tratamento, que apresenta menor custo de tratamento, ou utilizar um tratamento adicional, como a cloração ou UV. Este alto índice de coliformes presentes no efluente depois de tratado pode provocar a contaminação de várias culturas, sendo que as hortaliças folhosas, segundo Armon et al. (2002), são mais vulneráveis as contaminações. Algumas recomendações baseadas em dados microbiológicas têm sido estabelecidas para a irrigação com água residuária; no entanto, ainda persiste a necessidade de se definir um critério melhor elaborado para a qualidade dos efluentes para irrigação irrestrita de culturas, relacionando-as aos métodos de disposição.

Observa-se, pela Tabela 4, que na água residuária os teores de nitrogênio amônio $\left(\mathrm{N}-\mathrm{NH}_{4}^{+}\right)$foram, em média, de $35 \mathrm{mg} \mathrm{L}^{-1}$, considerados críticos para irrigação de hortaliças (Trani, 2001), enquanto na água do depósito não se detectou sua presença. Para Brasil (2005) na irrigação de hortaliças consumidas cruas o limite do nitrogênio amoniacal para $\mathrm{pH} \leq 7,5$, situação deste trabalho, é de $3,5 \mathrm{mg} \mathrm{L}^{-1}$; portanto, os resultados obtidos estão acima dos padrões recomendados por esta resolução. Os valores normais de $\mathrm{N}-\mathrm{NH}_{4}{ }^{+}$em água de irrigação estão entre 0 e 5,0 $\mathrm{mg} \mathrm{L}^{-1}$ (Ayers \& Westcot, 1991), mas em águas residuais domésticas ou das fábricas processadoras de alimentos, estão entre 10 e $50 \mathrm{mg} \mathrm{L}^{-1}$. Para a grande maioria das culturas, com exceção das hortaliças, não ocorrem efeitos prejudiciais com concentrações inferiores a $30 \mathrm{mg} \mathrm{L}^{-1}$. Na forma de nitrato na água residuária, o nitrogênio apresentou o maior valor aos 25 DAT, sendo de 1,2 $\mathrm{mg} \mathrm{L}^{-1}$. Para Ayers \& Westcot (1991), nos valores de até $5 \mathrm{mg} \mathrm{L}^{-1}$ de nitrato não existe restrição; de 5 a $30 \mathrm{mg} \mathrm{L}^{-1}$, a restrição é ligeira a moderada; já para Trani (2001) e Brasil (2005), os valores limites de nitrato são de até $10,0 \mathrm{mg} \mathrm{L}^{-1}$ na água de irrigação para hortaliças, para que não ocorram problemas de saúde aos consumidores de alimentos com excesso de nitrato e de contaminação de águas subterrâneas e superficiais (Boink \& Speijers, 2001). Por si só, a toxidez do nitrato em humanos é baixa; no entanto, de 5 a $10 \%$ do $\mathrm{NO}_{3}{ }^{-}$ingeridos na alimentação é convertido a nitrito $\left(\mathrm{NO}_{2}{ }^{-}\right)$ na saliva bucal ou por redução gastrointestinal; assim, o nitrito, entrando na corrente sangüínea, oxida o ferro $\left(\mathrm{Fe}^{2+} \rightarrow \mathrm{Fe}^{3+}\right)$ da hemoglobina, produzindo a metahemoglobina. O nitrogênio, facilmente assimilável pelas plantas, está na forma de nitrato e amônio, sendo este último, encontrado somente em águas residuais ou aplicados pelos fertilizantes que, se em concentrações altas, poderão ser benéficos durante as primeiras fases e prejudiciais durante a floração e frutificação das culturas, causando redução dos rendimentos, sendo uma medida útil à mistura ou mudança de água, porém, em plantas folhosas como a alface, repolho etc, o nitrogênio é benéfico, devendo ser tomadas precauções apenas quando ocorrer indícios de toxidez às plantas.

Os maiores teores de fósforo total na água residuária foram de 2,35 $\mathrm{mg} \mathrm{L}^{-1}$ inferiores, portanto, aos verificados por Miranda (1995), que observou valor médio de 9,4 $\mathrm{mg} \mathrm{L}^{-1}$ em efluente doméstico com tratamento secundário. Estes teores, de acordo com Brasil (2005), estão acima do permitido para a Classe 1, indicado para a irrigação de hortaliças consumidas cruas, o qual permite um valor máximo de fósforo total de $0,025 \mathrm{mg} \mathrm{L}^{-1}$ (ambiente intermediário, com tempo de residência entre 2 e 40 dias, e tributários 
diretos de ambiente lêntico). Os valores críticos de fósforo na água de irrigação, segundo Trani (2001) são de $30 \mathrm{mg} \mathrm{L}^{-1}$; contudo, observa-se grande disparidade entre as literaturas; referidas diferenças podem estar relacionadas aos objetivos do estudo deste parâmetro na água, embora para a água de irrigação o máximo de fósforo deva ser definido de forma que não ocorra a formação de precipitados, como bicarbonato de cálcio. Nas fontes de água, como em rios e lagos etc, o excesso de fósforo poderá favorecer o desenvolvimento de algas e causar a eutrofização da água. Outro aspecto importante do excesso de fósforo é que pode afetar o desenvolvimento da planta e interferir no seu equilíbrio nutricional; além disso, há possibilidade de causar danos à saúde humana.

Os valores de potássio na água residuária foram, no máximo, de $0,31 \mathrm{mmol}_{\mathrm{C}} \mathrm{L}^{-1}$ aos 45 DAT, não sendo o suficiente para causar qualquer sintoma de toxidez na alface; o mesmo foi constatado por Miranda (1995), cuja concentração média de potássio na água residuária foi de $0,64 \mathrm{mmol}_{\mathrm{C}} \mathrm{L}^{-1}$. Considerando-se o teor máximo de potássio, tem-se que o total adicionado ao solo via água residuária foi da ordem de $24 \mathrm{~kg} \mathrm{ha}^{-1}$, estimando-se que cerca de 0,37 mmol $_{\mathrm{C}} \mathrm{L}^{-1}$ de $\mathrm{K}_{2} \mathrm{O}$ estavam presentes. Na água do depósito superficial a concentração de potássio foi no máximo de 0,01 , valores esses normais para água de irrigação que, de acordo com Ayers \& Westcot (1991), estão entre 0 e $0,051 \mathrm{mmol}_{\mathrm{C}} \mathrm{L}^{-1}$. O potássio, adicionado ao solo, pode não estar completamente disponível para as plantas uma vez que, no solo, pode tomar diferentes formas (fixado, trocável ou constituinte da matéria orgânica). Para Trani (2001), os valores máximos permissíveis de potássio na água de irrigação para a aplicação em hortaliças folhosas, sem provocar perda de produtividade, estão entre 0,13 e 2,56 mmol $_{\mathrm{C}} \mathrm{L}^{-1}$ mostrando, desta forma, que a água utilizada não apresentou restrição alguma para uso na irrigação da alface.

O cálcio indicou valores próximos de 1,5 mmol $_{\mathrm{C}} \mathrm{L}^{-1}$ nos tratamentos em que se usou água residuária e, para o sódio, o valor máximo foi de $0,84 \mathrm{mmol}_{\mathrm{C}} \mathrm{L}^{-1}$ aos 25 DAT e mínimo de 0,78 mmol $_{\mathrm{C}} \mathrm{L}^{-1}$ aos 10 DAT; esses valores estão bem abaixo do encontrado por Miranda (1995), que verificou concentração média de 2,96 $\mathrm{mmol}_{\mathrm{C}} \mathrm{L}^{-1}$ para o sódio, sendo o mesmo verificado por Medeiros et al. (2005), que obtiveram valores médios de 1,83, 0,69 e 0,27 $\mathrm{mmol}_{\mathrm{C}} \mathrm{L}^{-1}$, para o $\mathrm{Na}$, Ca e $\mathrm{Mg}$, respectivamente, em água residuária com tratamento secundário. Considerando-se as diretrizes apresentadas por Ayers \& Westcot (1991), no que se refere à toxicidade de íons como o $\mathrm{Na}^{+}$, a água residuária não indicou restrições de uso em razão de apresentar concentração menor que 3,0 mmol $_{\mathrm{C}} \mathrm{L}^{-1}$, durante os dois ciclos da cultura. Crook (1991) e Trani (2001) relatam que danos severos somente ocorrem se os teores de sódio forem superiores ao valor citado acima, provocando absorção excessiva deste íon, especialmente se a umidade no solo for inferior a $30 \%$. A concentração de magnésio variou entre 0,16 e $0,25 \mathrm{mmol}_{\mathrm{C}} \mathrm{L}^{-1}$. Ayers \& Westcot (1991) relatam que, em águas normais de irrigação, as concentrações em geral possíveis de serem encontradas oscilam entre $0-20 \mathrm{mmol}_{\mathrm{C}} \mathrm{L}^{-1}$ para o cálcio, 0-5 para o magnésio e entre 0-40 para o sódio.
Na água do depósito superficial os maiores valores de $\mathrm{Na}$ e Ca foram de 0,087 e $0,37 \mathrm{mmol}_{\mathrm{c}} \mathrm{L}^{-1}$, respectivamente, bem inferiores aos observados na água residuária, enquanto os teores de $\mathrm{Mg}$ foram muito semelhantes, dentro, portanto dos limites aceitáveis para água de irrigação.

A razão máxima de absorção de sódio foi de $0,86\left(\mathrm{mmol} \mathrm{L}^{-1}\right)^{1 / 2}$ (Tabela 4$)$ na água residuária e de $0,21\left(\mathrm{mmol} \mathrm{L}^{-1}\right)^{1 / 2}$ para a água do depósito. De acordo com Ayers \& Westcot (1991), para RAS até $3\left(\mathrm{mmol} \mathrm{L}^{-1}\right)^{1 / 2}$, conjuntamente com EC menor que $0,7 \mathrm{dS} \mathrm{m}^{-1}$, não existe nenhum grau de restrição de uso para a água de irrigação, desta forma, observa-se que os valores de sódio e RAS da água residuária se apresentaram abaixo dos normalmente encontrados em água residuária, devido, possivelmente ao sistema de tratamento do efluente (leitos cultivados com macrófitas), removendo significativa quantidade de nutrientes, como nitrogênio, fósforo, potássio, sódio; observase também que a água com predominância dos íons de sódio pode promover a diminuição da permeabilidade do solo, causando redução da aeração do solo e inibição do desenvolvimento do sistema radicular das plantas com conseqüente redução de produção.

A condutividade elétrica da água (CE) residuária foi de $0,52 \mathrm{dS} \mathrm{m}^{-1}$ aos 10 e 25 DAT e de $0,63 \mathrm{dS} \mathrm{m}^{-1}$ aos 45 DAT. Considerando-se a classificação para a irrigação proposta por Ayers \& Westcot (1991), a água utilizada possuía salinidade sem nenhum grau de restrição, em que a CE pode chegar a até $0,7 \mathrm{dS} \mathrm{m}^{-1}$ (450 $\mathrm{mg} \mathrm{L}^{-1}$ de SDT), e ser utilizada na irrigação sem qualquer problema, até mesmo para culturas mais sensíveis a salinidade. Ainda conforme os autores acima, o valor de $1,3 \mathrm{dS} \mathrm{m}^{-1}$ é recomendado como sendo a máxima salinidade tolerada pela cultura da alface, sendo que o aumento da salinidade em uma unidade pode resultar em decréscimos na produção de 9,9\%.

Segundo a EPAV (1991), a CE da água residuária se caracteriza como de Classe $2(0,3$ a 0,8 dS m-1). Assim, a aplicação desta água por aspersão, com concentração próxima do limite superior, pode ocasionar leves queimaduras das folhas em culturas mais sensíveis aos sais, principalmente em altas temperaturas, durante o dia e com baixas taxas de aplicação.

O valor médio de pH na água residuária foi de 7,3 e, na do depósito, de 7,0, valores estes dentro do intervalo recomendado por Brasil (2005) para irrigação de hortaliças, que devem estar entre 6,0 e 9,0. Segundo classificação de Feigin et al. (1991), o valor do pH na água residuária é considerado médio em ambos os ciclos da cultura e, portanto, normal para uso na irrigação.

Os maiores valores de enxofre foram de 3,2 para a água residuária e de $1,5 \mathrm{mg} \mathrm{L}^{-1}$ água do depósito. Em geral, o enxofre provém da utilização do sulfato de amônio como fonte de nitrogênio nas aplicações complementares, já que possui enxofre em sua formulação, porém, em água residuária o enxofre apresenta valores elevados, mas, normalmente, não ocasiona qualquer tipo de problema às plantas.

Os teores de $\mathrm{DBO}$ observados em praticamente todos os tratamentos e datas de amostragem se encontraram acima do máximo permitido para a Classe 1 , que é de até $3 \mathrm{mg} \mathrm{L}^{-1}$ 
(Brasil, 2005); observa-se, porém, grande variação da DBO entre as datas de amostragem, em virtude da qualidade do efluente tratado, que apresenta variações em função da intensidade de uso das dependências da universidade, tanto durante os dias da semana como durante o período do dia, além de possíveis variações de vazão de entrada no sistema de tratamento do efluente e das condições climáticas (principalmente a incidência de chuvas no final do $2^{\circ}$ ciclo da cultura), no período de coleta das amostras de água, como ocorreu .

O teor máximo de boro, considerando-se a água residuá-

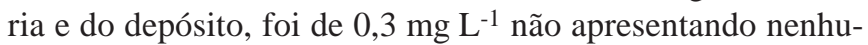
ma restrição para aplicação na irrigação que, de acordo com Ayers \& Westcot (1991), poderá haver problema quando a concentração atingir pelo menos $0,7 \mathrm{mg} \mathrm{L}^{-1}$, enquanto para Trani (2001), os valores limites para a água de irrigação estão entre 0,5 a 1,0 mg L-1. O limite máximo, para Brasil (2005) na água de irrigação da Classe 1 , é de $0,5 \mathrm{mg} \mathrm{L}^{-1}$. Os limites recomendados de boro em águas residuárias utilizadas na irrigação em curto prazo, podem ser de até $2 \mathrm{mg} \mathrm{L}^{-1}$ (Crook, 1991). A alta concentração de boro pode ser encontrada em efluente doméstico, normalmente entre 0,5 a $1,0 \mathrm{mg} \mathrm{L}^{-1}$, atribuída ao uso de componentes à base de boro em produtos de limpeza (Kirkam, 1986).

Na água residuária, a concentração de ferro não ultrapassou de $1,1 \mathrm{mg} \mathrm{L}^{-1}$ e, na água do depósito, de $0,9 \mathrm{mg} \mathrm{L}^{-1}$. De acordo com Trani \& Carrijo (2004) os valores máximos de ferro na água de irrigação devem estar entre 0,2 a 1,5 $\mathrm{mg} \mathrm{L}^{-1}$, visto que, acima deste limite superior, pode ocorrer precipitação de $\mathrm{F}_{2} \mathrm{Cl}_{3}$ em águas com altos teores de cloro. Os valores menores de ferro total devem ser utilizados em culturas que são consumidas cruas, como indicação de Brasil (2005), que recomenda o limite máximo de $0,3 \mathrm{mg} \mathrm{L}^{-1}$.

Conhecer e quantificar as características químicas da água residuária para irrigação de culturas é essencial para que a partir dessas análises, se observem os padrões máxi- mos definidos pela resolução CONAMA nº 357 (Brasil, 2005), para as diferentes classes de uso e, também, as referências especializadas na área, com a finalidade de evitar danos ao solo e ao meio ambiente, toxidez às plantas, contaminação de fontes de água e problemas à saúde humana e animal.

Considerando-se as concentrações de nutrientes analisadas na água residuária e na água do depósito e as lâminas aplicadas ao solo via irrigação, estimou-se o potencial fertilizante (Tabela 5). A quantidade de Na aplicada ao solo pela água residuária durante o $1^{\circ}$ ciclo foi de 12,90, 13,5 e 14,2 $\mathrm{kg} \mathrm{ha}^{-1}$ e, durante o $2^{\circ}$ ciclo, de 23,7, 25,1 e $26,7 \mathrm{~kg} \mathrm{ha}^{-1}$, respectivamente, para os tratamentos GSpR, GSbR e AR, sendo consideradas mais elevadas quando comparadas com as da irrigação com água superficial, taxas essas, inferiores as obtidas por Medeiros et al. (2005), que observaram valores oscilando entre 92,93 a 241,9 $\mathrm{kg} \mathrm{ha}^{-1}$. Os autores afirmam que destas taxas podem se constituírem num fator limitante para o uso da água residuária de origem doméstica na agricultura, em razão da possibilidade de acúmulo de sódio ao longo do tempo, no entanto, práticas especiais de manejo, como aplicação de lâminas de lixiviação, aplicação de água superficial em determinados períodos e a suspensão da aplicação da água residuária durante o período chuvoso, podem contribuir para a lixiviação do sódio abaixo da zona radicular, evitando problemas de toxicidade.

A água residuária utilizada evidencia possuir potencial como fonte de nutriente, estando de acordo com as diretrizes para uso na irrigação durante longo período, para a grande maioria dos nutrientes. Atenção especial deve ser dada ao nitrogênio que apresentou níveis acima dos considerados adequados para água de irrigação, e ao sódio, onde há possibilidade de acúmulo do mesmo ao longo do tempo, exigindo práticas especiais de manejo, conforme descrito por Medeiros et al. (2005).

Tabela 5. Taxas de nutrientes aplicados ao solo, via água residuária e água de depósito, durante os $1^{\circ}$ e $2^{\circ}$ ciclos da cultura, para todos os tratamentos

\begin{tabular}{|c|c|c|c|c|c|c|c|c|c|c|c|c|}
\hline Tratamentos & $\begin{array}{c}\text { Lâminas } \\
\text { acumuladas }(\mathrm{mm})\end{array}$ & $P$ & \multicolumn{9}{|c|}{$\left(\mathrm{kg} \mathrm{ha}^{-1}\right)$} & $\bar{B}$ \\
\hline & & \multicolumn{11}{|c|}{$1^{0}$ ciclo } \\
\hline GSpR & 72,1 & 1,11 & 2,53 & 6,85 & 20,85 & 0,24 & 12,86 & 23,32 & 1,56 & 1,56 & 0,70 & 0,1 \\
\hline GSbR & 75,8 & 1,16 & 2,66 & 7,20 & 21,91 & 0,25 & 13,52 & 24,51 & 1,64 & 1,64 & 0,73 & 0,1 \\
\hline$A R$ & 79,5 & 1,22 & 2,79 & 7,55 & 22,98 & 0,27 & 14,18 & 25,71 & 1,72 & 1,72 & 0,77 & 0,1 \\
\hline GSpD & 73,0 & 0,03 & 0,07 & 0,55 & 0,00 & 0,17 & 1,22 & 4,26 & 1,34 & 0,73 & 0,49 & * \\
\hline GSbD & 74,7 & 0,03 & 0,07 & 0,56 & 0,00 & 0,17 & 1,25 & 4,36 & 1,37 & 0,75 & 0,50 & * \\
\hline$A D$ & 80,6 & 0,03 & 0,08 & 0,60 & 0,00 & 0,19 & 1,34 & 4,70 & 1,48 & 0,81 & 0,54 & * \\
\hline \multirow[t]{2}{*}{ GSpR } & 72,1 & 1,11 & 2,53 & 6,85 & 20,85 & 0,24 & 12,86 & 23,32 & 1,56 & 1,56 & 0,70 & 0,1 \\
\hline & & \multicolumn{11}{|c|}{$2^{0}$ ciclo } \\
\hline GSpR & 127,2 & 1,95 & 4,45 & 12,08 & 36,75 & 0,42 & 22,68 & 41,11 & 2,76 & 2,76 & 1,23 & 0,13 \\
\hline GSbR & 134,5 & 2,07 & 4,71 & 12,78 & 38,87 & 0,45 & 23,98 & 43,48 & 2,91 & 2,91 & 1,30 & 0,13 \\
\hline AR & 142,7 & 2,19 & 5,00 & 13,55 & 41,23 & 0,48 & 25,44 & 46,13 & 3,09 & 3,09 & 1,38 & 0,14 \\
\hline GSpD & 127,9 & 0,06 & 0,12 & 0,96 & 0,00 & 0,30 & 2,13 & 7,46 & 2,34 & 1,28 & 0,85 & * \\
\hline GSbD & 131,2 & 0,06 & 0,13 & 0,98 & 0,00 & 0,31 & 2,19 & 7,65 & 2,41 & 1,31 & 0,87 & * \\
\hline$A D$ & 143,2 & 0,06 & 0,14 & 1,07 & 0,00 & 0,33 & 2,39 & 8,35 & 2,62 & 1,43 & 0,95 & * \\
\hline GSpR & 127,2 & 1,95 & 4,45 & 12,08 & 36,75 & 0,42 & 22,68 & 41,11 & 2,76 & 2,76 & 1,23 & 0,13 \\
\hline
\end{tabular}

* Abaixo do limite de detecção

AR: aspersão com água residuária; AD: aspersão com água do depósito; GSbR: gotejamento subterrâneo com água residuária; GSbD: gotejamento subterrâneo com água do depósito; GSpR: gotejamento superficial com água residuária e GSpD: gotejamento superficial com água do depósito 


\section{Crescimento e desenvolvimento da alface}

Altura: Os valores médios da altura da alface durante o $1^{\circ}$ ciclo apresentaram diferença significativa aos 25 DAT entre a água residuária e a do depósito, aplicadas na aspersão (Tabela 6), também diferiram entre si, os três sistemas de irrigação, utilizando-se água residuária e água do depósito, enquanto a aspersão diferiu do gotejamento superficial; constatou-se que, no $2^{\circ}$ ciclo, com água residuária aos 14 DAT a aspersão diferiu do gotejamento subterrâneo e superficial, podendo ser devido à variabilidade entre as plantas em cada tratamento; nessa data de amostragem também ocorreu diferença significativa entre os tratamentos GSpR e GSpD e se observa que a maior produção de massa fresca nos tratamentos com água residuária não resultou em diferenciação na altura das folhas. Hamada (1995), não observou, em seu estudo com alface, diferença significativa na altura em nenhuma das datas de amostragem, considerando as lâminas de irrigação de 60, 80, 100 e 120\% da evaporação do tanque "Classe A".

Número de folhas: No $1^{\circ}$ ciclo, se notou, aos 33 DAT, diferença significativa no número de folhas entre as plantas irrigadas com água residuária e água do depósito no gotejamento superficial, enquanto aos 39 e 45 DAT a diferença ocorreu no gotejamento subterrâneo, entre as duas qualidades de água; já aos 45 DAT as médias diferiram, tanto na aspersão como no gotejamento subterrâneo. Por outro lado, aos 33, 39 e 45 DAT ocorreu diferença entre a aspersão e o gotejamento subterrâneo no qual se utilizou água residuária (Tabela 6).

Observou-se, no $2^{\circ}$ ciclo, diferença significativa entre a água residuária e a água do depósito, tanto no gotejamento subterrâneo como no superficial, aos 33 e 41 DAT. A aspersão e o gotejamento subterrâneo diferiram do gotejamento superficial aos 33 DAT utilizando água residuária e aos 41 DAT a aspersão diferiu não apenas do gotejamento subterrâneo, mas também, do superficial.

No $1^{\circ}$ ciclo, o maior número médio de folhas por planta (38) foi obtido nos tratamentos (45 DAT): água residuária, irrigação por gotejamento subterrâneo e superficial e água do depósito, irrigação por aspersão; no $2^{\circ}$ ciclo (47 DAT), os maiores valores médios foram de 54 na irrigação por gotejamento subterrâneo e superficial com água residuária. Nota-se que o número de folhas por planta foi maior no $2^{\circ}$ ciclo em todos os tratamentos, fato que pode ser atribuído a um possível efeito cumulativo de alguns nutrientes no solo, uma vez que os dois ciclos foram realizados no mesmo local, e também às condições climáticas mais favoráveis: temperaturas mais elevadas e maior precipitação. Andrade Junior et al. (2005) avaliaram o efeito de diferentes coberturas de canteiro (plástico preto, capim braquiária seco, casca de arroz, casca de café e solo nu) sobre as características agronômicas das cultivares de alface tipo lisa (Regina e Elisa) em Três Corações, MG, utilizando a irrigação por aspersão, elevando-se o teor de água no solo próximo à capacidade de campo, durante todo o ciclo da cultura, observando que aos 42 DAT o número máximo de folhas obtido para a cultivar Elisa foi de 28 (casca de café) e o mínimo de 19 (capim braquiária seco). Gomes et al. (2005) estudaram a influência de doses de $\mathrm{CO}_{2}$ de 0, 52, 155 e $310 \mathrm{~kg} \mathrm{ha}^{-1}$, aplicadas via água de irrigação por gotejamento, utilizando com cilindro com fluxômetro na escala de 0,2 a 2,0 $\mathrm{L} \mathrm{min}^{-1}$, onde avaliaram o desenvolvimento, a fotossíntese e a produtividade da alface cultivar Elisa, além de seus efeitos sobre a condutividade elétrica, notando que o número de folhas foi influenciado pela aplicação de $\mathrm{CO}_{2}$, obtendo valor máximo de 29 folhas para a dose $155 \mathrm{~kg} \mathrm{ha}^{-1}$.

Massa fresca total: O comportamento de ganho de massa fresca é típico da cultura da alface, com crescimento lento no início do ciclo e elevado no seu final, similares ao acúmulo de massa seca total (Tabela 6). Durante o $1^{\circ}$ ciclo da cultura da alface correu diferença significativa na massa fresca total, no gotejamento subterrâneo a partir dos 33 DAT até o final do ciclo, enquanto no gotejamento superficial a diferença significativa se deu na última data de amostragem. Foi notória a diferença da massa fresca entre a aspersão e o gotejamento subterrâneo utilizando água residuária a partir dos 25 DAT mas, em relação ao gotejamento superficial, a aspersão diferiu nas datas de amostragem de 33 e 45 DAT.

A diferença significativa no $2^{\circ}$ ciclo entre a água residuária e do depósito, se deu tanto no gotejamento subterrâneo como no superficial, nas amostragens de 25, 33 e 41 DAT, enquanto aos 47 DAT as médias se igualaram. Aos 33 DAT notou-se diferença significativa entre a aspersão e o gotejamento superficial com água residuária; por outro lado e se utilizando água do depósito, constatou-se diferença da aspersão em relação ao gotejamento subterrâneo e superficial.

Dantas \& Escobedo (1998), avaliaram a alface Elisa, no verão de 1995/96 e no inverno de 1996, em ambientes protegidos e em condições naturais ou externas, utilizando a irrigação por gotejamento. Observaram que no verão os máximos valores da área foliar específica se apresentaram na quarta semana após o transplante nos ambientes protegidos e externo, com destaque maior para o ambiente protegido, que atingiu o valor máximo absoluto. Na segunda semana, após o transplante o crescimento da matéria seca no ambiente protegido foi maior que o crescimento da área foliar; constataram, ainda, que, de maneira geral, no verão o crescimento da matéria seca foi maior que o crescimento da área foliar a partir dos 29 DAT.

Observou-se, ainda, que nas duas primeiras datas de amostragem, tanto no $1^{\circ}$ como no $2^{\circ}$ ciclos, o ganho de massa fresca foi pequeno comparado com as datas de amostragens até o final do ciclo. Na última data de amostragem a curva de crescimento foi mais lenta em relação ao período intermediário do ciclo, principalmente no $2^{\circ}$ ciclo, com exceção do tratamento AR, que manteve o mesmo ritmo de crescimento até a última data de amostragem.

Evidenciou-se que o maior valor de massa fresca total ocorreu nos gotejamentos subterrâneo e superficial com água residuária, tanto no $1^{\circ}$ como no $2^{\circ}$ ciclos, podendo ser atribuído ao maior aporte de nutrientes nos tratamentos com água residuária.

De maneira geral, e durante o $1^{\circ}$ ciclo, aproximadamente 75 a $80 \%$ da massa fresca total final foram produzidos nas duas últimas datas de amostragem, ou seja, 12 dias antes da colheita, para todos os tratamentos, mostrando que o efeito 
Tabela 6. Média da altura da planta, número de folhas, massa fresca, massa seca e área foliar, para as cinco amostragens ao longo dos $1^{\circ}$ e $2^{\circ}$ ciclos

\begin{tabular}{|c|c|c|c|c|c|c|c|c|c|c|}
\hline \multirow{2}{*}{ Tratamentos } & \multicolumn{5}{|c|}{ Dias após o transplantio - $1^{0}$ ciclo } & \multicolumn{5}{|c|}{ Dias após o transplantio $-2^{0}$ ciclo } \\
\hline & 13 & 25 & 33 & 39 & 45 & 14 & 25 & 33 & 41 & 47 \\
\hline & \multicolumn{10}{|c|}{ Altura da planta $(\mathrm{cm})$} \\
\hline$A R$ & $8,0 \mathrm{Aa}$ & $12,0 \mathrm{Ca}$ & $15,1 \mathrm{Aa}$ & $16,9 \mathrm{Aa}$ & $19,2 \mathrm{Aa}$ & $8,9 \mathrm{Ba}$ & $12,8 \mathrm{Aa}$ & $15,9 \mathrm{Aa}$ & $19,1 \mathrm{Aa}$ & $22,0 \mathrm{Aa}$ \\
\hline GSbR & $8,9 \mathrm{Aa}$ & $15,1 \mathrm{Aa}$ & $17,3 \mathrm{Aa}$ & $19,5 \mathrm{Aa}$ & $20,7 \mathrm{Aa}$ & 9,9 ABa & $13,4 \mathrm{Aa}$ & $15,5 \mathrm{Aa}$ & $19,1 \mathrm{Aa}$ & $21,5 \mathrm{Aa}$ \\
\hline GSpR & $9,5 \mathrm{Aa}$ & $13,5 \mathrm{Ba}$ & $17,2 \mathrm{Aa}$ & $18,7 \mathrm{Aa}$ & $22,1 \mathrm{Aa}$ & $11,2 \mathrm{Aa}$ & $12,6 \mathrm{Aa}$ & $15,4 \mathrm{Aa}$ & $19,2 \mathrm{Aa}$ & $21,5 \mathrm{Aa}$ \\
\hline$A D$ & $8,6 \mathrm{Aa}$ & $11,9 \mathrm{Bb}$ & $16,1 \mathrm{Aa}$ & $18,0 \mathrm{Aa}$ & $21,5 \mathrm{Aa}$ & $9,3 \mathrm{Aa}$ & $12,6 \mathrm{Aa}$ & $16,0 \mathrm{Aa}$ & $20,7 \mathrm{Aa}$ & $21,0 \mathrm{Aa}$ \\
\hline GSbD & $8,7 \mathrm{Aa}$ & $12,7 \mathrm{ABa}$ & $16,6 \mathrm{Aa}$ & $17,8 \mathrm{Aa}$ & $19,7 \mathrm{Aa}$ & $9,6 \mathrm{Aa}$ & $12,0 \mathrm{Aa}$ & $14,2 \mathrm{Aa}$ & $18,3 \mathrm{Aa}$ & $21,4 \mathrm{Aa}$ \\
\hline GSpD & $9,4 \mathrm{Aa}$ & $13,8 \mathrm{Aa}$ & $16,2 \mathrm{Aa}$ & $17,8 \mathrm{Aa}$ & $19,8 \mathrm{Aa}$ & $9,3 \mathrm{Ab}$ & $12,0 \mathrm{Aa}$ & $14,6 \mathrm{Aa}$ & $19,2 \mathrm{Aa}$ & $21,5 \mathrm{Aa}$ \\
\hline Média & 8,82 & 13,17 & 16,40 & 18,13 & 20,46 & 9,69 & 12,59 & 15,52 & 19,25 & 21,51 \\
\hline Teste $\mathrm{F}^{1}$ & $1,17 \mathrm{~ns}$ & $8,17^{*}$ & $2,76 \mathrm{~ns}$ & $2,39 \mathrm{~ns}$ & $4,58 \mathrm{~ns}$ & $5,13^{*}$ & $1,02 \mathrm{~ns}$ & $2,97 \mathrm{~ns}$ & $1,44 \mathrm{~ns}$ & $0,50 \mathrm{~ns}$ \\
\hline DESVPAD & 0,56 & 0,64 & 0,77 & 1,15 & 1,34 & 0,64 & 0,73 & 0,80 & 1,26 & 0,98 \\
\hline \multirow[t]{2}{*}{ C.V. (\%) } & 8,82 & 4,83 & 16,40 & 6,32 & 6,54 & 6,55 & 5,80 & 5,13 & 6,56 & 4,54 \\
\hline & \multicolumn{10}{|c|}{ Número de folhas } \\
\hline AR & $8 \mathrm{Aa}$ & $14 \mathrm{Aa}$ & $22 \mathrm{Ba}$ & $29 \mathrm{Ba}$ & $33 \mathrm{Bb}$ & $9 \mathrm{Aa}$ & $19 \mathrm{Aa}$ & $30 \mathrm{Ba}$ & $39 \mathrm{Ba}$ & $48 \mathrm{Aa}$ \\
\hline GSbR & $8 \mathrm{Aa}$ & $18 \mathrm{Aa}$ & $27 \mathrm{Aa}$ & $33 \mathrm{Aa}$ & $38 \mathrm{Aa}$ & $10 \mathrm{Aa}$ & $21 \mathrm{Aa}$ & $31 \mathrm{Ba}$ & $46 \mathrm{Aa}$ & $54 \mathrm{Aa}$ \\
\hline GSpR & $7 \mathrm{Aa}$ & $16 \mathrm{Aa}$ & $24 \mathrm{ABb}$ & $31 \mathrm{ABa}$ & $38 \mathrm{Aa}$ & $10 \mathrm{Aa}$ & $18 \mathrm{Aa}$ & $33 \mathrm{Aa}$ & $46 \mathrm{Aa}$ & $54 \mathrm{Aa}$ \\
\hline$A D$ & $8 \mathrm{Aa}$ & $16 \mathrm{Aa}$ & $24 \mathrm{Aa}$ & $31 \mathrm{Aa}$ & $38 \mathrm{Aa}$ & $7 \mathrm{Aa}$ & $19 \mathrm{Aa}$ & $28 \mathrm{Aa}$ & $39 \mathrm{Aa}$ & $46 \mathrm{Aa}$ \\
\hline $\mathrm{GSbD}$ & $8 \mathrm{Aa}$ & $17 \mathrm{Aa}$ & $24 \mathrm{Aa}$ & $29 \mathrm{Ab}$ & $34 \mathrm{Ab}$ & $8 \mathrm{Aa}$ & $15 \mathrm{Aa}$ & $27 \mathrm{Ab}$ & $40 \mathrm{Ab}$ & $49 \mathrm{Aa}$ \\
\hline GSpD & $9 \mathrm{Aa}$ & $17 \mathrm{Aa}$ & $27 \mathrm{Aa}$ & $29 \mathrm{Aa}$ & $36 \mathrm{Aa}$ & $8 \mathrm{Aa}$ & $16 \mathrm{Aa}$ & $27 \mathrm{Ab}$ & $39 \mathrm{Ab}$ & $50 \mathrm{Aa}$ \\
\hline Média & 8 & 16 & 25 & 30 & 36 & 9 & 18 & 29 & 42 & 50 \\
\hline Teste $\mathrm{F}^{1}$ & $4,63^{*}$ & $3,58 \mathrm{~ns}$ & $6,50^{*}$ & $8,83^{*}$ & $11,38^{*}$ & $0,10 \mathrm{~ns}$ & $3,61 \mathrm{~ns}$ & $17,11^{*}$ & $7,58^{*}$ & $0,63 \mathrm{~ns}$ \\
\hline DESVPAD & 0,67 & 1,31 & 1,45 & 1,37 & 1,76 & 0,75 & 1,51 & 1,03 & 1,63 & 2,36 \\
\hline \multirow[t]{2}{*}{ C.V. (\%) } & 8,45 & 8,03 & 5,85 & 30,28 & 4,89 & 8,49 & 8,31 & 3,49 & 3,91 & 4,67 \\
\hline & \multicolumn{10}{|c|}{ Massa fresca $\left(\mathrm{g} \mathrm{planta}^{-1}\right)$} \\
\hline$A R$ & $2,7 \mathrm{Aa}$ & $12,0 \mathrm{Ca}$ & $41,3 \mathrm{Bb}$ & $90,7 \mathrm{Ba}$ & $115,9 \mathrm{Bb}$ & $2,7 \mathrm{Ba}$ & $19,1 \mathrm{Aa}$ & $64,0 \mathrm{Aa}$ & $156,0 \mathrm{Aa}$ & $244,2 \mathrm{Aa}$ \\
\hline GSbR & $3,9 \mathrm{Aa}$ & $30,0 \mathrm{Aa}$ & $85,7 \mathrm{Aa}$ & $163,1 \mathrm{Aa}$ & $207,0 \mathrm{Aa}$ & $3,5 \mathrm{Ba}$ & $21,5 \mathrm{Aa}$ & $63,89 \mathrm{Ba}$ & $189,5 \mathrm{Aa}$ & $256,3 \mathrm{Aa}$ \\
\hline GSpR & $3,9 \mathrm{Aa}$ & $19,3 \mathrm{Ba}$ & $69,2 \mathrm{Aa}$ & $133,2 \mathrm{ABa}$ & $214,8 \mathrm{Aa}$ & $4,6 \mathrm{Aa}$ & $19,3 \mathrm{Aa}$ & $70,0 \mathrm{Aa}$ & $191,4 \mathrm{Aa}$ & $260,5 \mathrm{Aa}$ \\
\hline$A D$ & $2,9 \mathrm{Aa}$ & $15,7 \mathrm{Aa}$ & $55,6 \mathrm{Aa}$ & $103,5 \mathrm{Aa}$ & $170,4 \mathrm{Aa}$ & $1,9 \mathrm{Aa}$ & $18,3 \mathrm{Aa}$ & $48,4 \mathrm{Aa}$ & $168,3 \mathrm{Aa}$ & $188,5 \mathrm{Aa}$ \\
\hline GSbD & $3,2 \mathrm{Aa}$ & $13,9 \mathrm{Ab}$ & $53,6 \mathrm{Ab}$ & $86,6 \mathrm{Ab}$ & $128,0 \mathrm{Ab}$ & $2,0 \mathrm{Ab}$ & $13,1 \mathrm{Ab}$ & $39,4 \mathrm{Ab}$ & $121,5 \mathrm{Ba}$ & $175,4 \mathrm{Aa}$ \\
\hline GSpD & 4,2 Aa & $18,2 \mathrm{Aa}$ & $57,3 \mathrm{Aa}$ & $94,4 \mathrm{Ab}$ & $151,4 \mathrm{Ab}$ & $2,2 \mathrm{Ab}$ & $13,4 \mathrm{Aa}$ & $39,7 \mathrm{Ab}$ & $124,9 \mathrm{Bb}$ & $190,0 \mathrm{Aa}$ \\
\hline Média & 3,5 & 18,2 & 60,4 & 111,5 & 164,6 & 2,8 & 18,0 & 56,4 & 158,6 & 219,1 \\
\hline Teste $F^{1}$ & $1,25 \mathrm{~ns}$ & $14,57^{*}$ & $12,91^{*}$ & $7,46^{*}$ & $14,16^{*}$ & $5,33^{*}$ & $5,26^{*}$ & $6,53^{*}$ & $9,45^{*}$ & $0,48 \mathrm{~ns}$ \\
\hline DESVPAD & 0,58 & 3,31 & 7,97 & 20,61 & 23,76 & 0,43 & 2,49 & 6,82 & 18,31 & 22,47 \\
\hline \multirow[t]{2}{*}{ C.V. (\%) } & 16,86 & 18,17 & 13,18 & 18,47 & 14,44 & 15,19 & 13,87 & 12,09 & 11,54 & 10,26 \\
\hline & \multicolumn{10}{|c|}{ Massa seca (g planta-1) } \\
\hline$A R$ & $0,16 \mathrm{Aa}$ & $0,73 \mathrm{Cb}$ & $2,44 \mathrm{Ca}$ & $5,82 \mathrm{Ba}$ & $6,62 \mathrm{Bb}$ & $0,30 \mathrm{Aa}$ & $1,50 \mathrm{Aa}$ & 4,41 Ba & $8,77 \mathrm{Aa}$ & $11,52 \mathrm{Aa}$ \\
\hline GSbR & $0,19 \mathrm{Aa}$ & $1,79 \mathrm{Aa}$ & $4,87 \mathrm{Aa}$ & $8,93 \mathrm{Aa}$ & $9,27 \mathrm{Aa}$ & $0,36 \mathrm{Aa}$ & $1,83 \mathrm{Aa}$ & $4,80 \mathrm{Ba}$ & $10,72 \mathrm{Aa}$ & $12,98 \mathrm{Aa}$ \\
\hline GSpR & $0,20 \mathrm{Aa}$ & $1,20 \mathrm{Ba}$ & $3,87 \mathrm{Ba}$ & $7,88 \mathrm{ABa}$ & $10,08 \mathrm{Aa}$ & $0,45 \mathrm{Aa}$ & $1,59 \mathrm{Aa}$ & $5,19 \mathrm{Aa}$ & $10,23 \mathrm{Aa}$ & $13,30 \mathrm{Aa}$ \\
\hline$A D$ & $0,17 \mathrm{Aa}$ & $1,10 \mathrm{Aa}$ & 3,07 Aa & $6,18 \mathrm{Aa}$ & $8,03 \mathrm{Aa}$ & $0,17 \mathrm{Aa}$ & $1,38 \mathrm{Aa}$ & 3,95 Aa & $8,93 \mathrm{Aa}$ & $9,53 \mathrm{Aa}$ \\
\hline GSbD & $0,18 \mathrm{Aa}$ & $0,93 \mathrm{Ab}$ & $3,35 \mathrm{Ab}$ & $6,12 \mathrm{Ab}$ & $7,43 \mathrm{Ab}$ & $0,24 \mathrm{Aa}$ & $1,17 \mathrm{Aa}$ & $3,12 \mathrm{Ab}$ & $7,20 \mathrm{Ab}$ & $9,42 \mathrm{Aa}$ \\
\hline GSpD & $0,22 \mathrm{Aa}$ & $1,18 \mathrm{Aa}$ & 3,43 Аa & $6,76 \mathrm{Aa}$ & $8,28 \mathrm{Ab}$ & $0,23 \mathrm{Aa}$ & $1,14 \mathrm{Aa}$ & $3,17 \mathrm{Ab}$ & $6,97 \mathrm{~A}, \mathrm{~b}$ & $9,98 \mathrm{~A}, \mathrm{a}$ \\
\hline Média & 0,19 & 1,16 & 3,51 & 7,00 & 8,37 & 0,28 & 1,48 & 4,27 & 8,80 & 11,13 \\
\hline Teste $\mathrm{F}^{1}$ & $0,24 \mathrm{~ns}$ & $23,39 *$ & $12,46^{*}$ & $4,94^{*}$ & $13,19 *$ & $1,38 \mathrm{~ns}$ & $3,57 \mathrm{~ns}$ & $12,67^{*}$ & $4,47^{*}$ & $0,38 \mathrm{~ns}$ \\
\hline DESVPAD & 0,03 & 0,16 & 0,37 & 0,97 & 0,69 & 16,67 & 14,03 & 10,31 & 13,54 & 9,90 \\
\hline \multirow[t]{2}{*}{ C.V. (\%) } & 16,95 & 13,76 & 10,59 & 13,84 & 8,21 & 16,67 & 14,03 & 10,31 & 13,54 & 9,90 \\
\hline & \multicolumn{10}{|c|}{ Área foliar (cm² planta $\left.^{-1}\right)$} \\
\hline AR & $78,50 \mathrm{Aa}$ & $325,57 \mathrm{Ca}$ & $944,40 \mathrm{Bb}$ & $2062,00 \mathrm{Ba}$ & $2669,25 \mathrm{Bb}$ & $92,86 \mathrm{Ca}$ & $499,59 \mathrm{Aa}$ & $1573,78 \mathrm{Ba}$ & $3479,62 \mathrm{Aa}$ & $5748,89 \mathrm{Aa}$ \\
\hline GSbR & $108,16 \mathrm{Aa}$ & $752,68 \mathrm{Aa}$ & $1852,05 \mathrm{Aa}$ & $3616,44 \mathrm{Aa}$ & $4376,73 \mathrm{Aa}$ & $123,24 \mathrm{Ba}$ & $575,97 \mathrm{Aa}$ & $1567,03 \mathrm{Ba}$ & $4303,76 \mathrm{Aa}$ & $5948,43 \mathrm{Aa}$ \\
\hline GSpR & $116,94 \mathrm{Aa}$ & $497,34 \mathrm{Ba}$ & $1558,38 \mathrm{Aa}$ & $3075,23 \mathrm{ABa}$ & $4790,63 \mathrm{Aa}$ & $152,92 \mathrm{Aa}$ & $507,73 \mathrm{Aa}$ & $1807,02 \mathrm{Aa}$ & $4151,49 \mathrm{Aa}$ & $5927,25 \mathrm{Aa}$ \\
\hline$A D$ & $89,50 \mathrm{Aa}$ & 410,88 Аа & $1263,91 \mathrm{Aa}$ & $2517,95 \mathrm{Aa}$ & $3922,66 \mathrm{Aa}$ & $71,46 \mathrm{Aa}$ & $49921 \mathrm{Aa}$ & $1217,50 \mathrm{Ab}$ & $3980,09 \mathrm{Aa}$ & $4386,89 \mathrm{Aa}$ \\
\hline GSbD & $92,30 \mathrm{Aa}$ & $383,39 \mathrm{Ab}$ & $1258,97 \mathrm{Ab}$ & $2057,22 \mathrm{Ab}$ & $3263,88 \mathrm{Ab}$ & $72,16 \mathrm{Ab}$ & $370,29 \mathrm{Ab}$ & $985,88 \mathrm{Ab}$ & $2830,31 \mathrm{Bb}$ & $4148,76 \mathrm{Aa}$ \\
\hline GSpD & $120,30 \mathrm{Aa}$ & $528,43 \mathrm{Aa}$ & $1381,12 \mathrm{Aa}$ & $2292,26 \mathrm{Aa}$ & $3740,54 \mathrm{Ab}$ & $73,90 \mathrm{Ab}$ & $380,46 \mathrm{Ab}$ & $1157,90 \mathrm{Ab}$ & $2878,36 \mathrm{Bb}$ & $4582,45 \mathrm{Aa}$ \\
\hline Média & 100,95 & 483,05 & 1374,76 & 2603,51 & 3793,95 & 97,76 & 485,63 & 1456,17 & 3603,94 & 5123,78 \\
\hline Teste $\mathrm{F}^{1}$ & $1,09 \mathrm{~ns}$ & $15,65^{*}$ & $13,65^{*}$ & $5,10^{*}$ & $9,94^{*}$ & $7,90^{*}$ & $4,85^{*}$ & $7,21^{*}$ & $7,88^{*}$ & $0,37 \mathrm{~ns}$ \\
\hline DESVPAD & 16,24 & 76,86 & 149,81 & 551,22 & 523,89 & 12,56 & 66,27 & 168,26 & 474,02 & 519,04 \\
\hline C.V. (\%) & 16,09 & 15,91 & 10,89 & 21,17 & 13,81 & 12,85 & 13,65 & 11,55 & 13,15 & 10,13 \\
\hline
\end{tabular}

Médias seguidas por letras distintas diferem entre si a nível de $5 \%$ pelo teste de Tukey AR: aspersão com água residuária; $\mathrm{AD}$ : aspersão com água do depósito; GSbR: gotejamento subterrâneo com água residuária; GSbD: gotejamento subterrâneo com água do depósito; GSpR: gotejamento superficial com água residuária e GSpD: gotejamento superficial com água do depósito

Teste $\mathrm{F}$ para a interação tipo de água $\mathrm{x}$ tipo de irrigação 
cumulativo de massa fresca total se deve mais ao comportamento do crescimento da própria cultura que simplesmente ao efeito da presença de nutriente; já no $2^{\circ}$ ciclo esses índices foram mais elevados, porém, com pequena alteração, situando-se entre 80 e $85 \%$ da massa fresca total produzida nas duas últimas datas de amostragem, o que corresponde a 14 dias antes da colheita, em todos os tratamentos; esses resultados são semelhantes aos encontrados por Hamada (1995), que estudou a utilização da irrigação por gotejamento, considerando lâmina de irrigação de 60, 80, 100 e 120\% da evaporação do tanque "Classe A", constatando que aproximadamente 80 a $90 \%$ de toda a massa fresca de alface americana foram produzidos nas duas últimas semanas antes da colheita, cujas maiores porcentagens foram obtidas pelas maiores lâminas de água.

No $2^{\circ}$ ciclo a produção de massa fresca total foi maior em relação ao $1^{\circ}$, em todos os tratamentos, variando de 244,2 a 260,5 g por planta nos tratamentos em que se utilizou água residuária, e de 175,4 a 190,0 g por planta com água do depósito, mostrando que a água residuária proporcionou maior produção de massa fresca quando comparada com a água do depósito, devido ao efeito cumulativo de nutrientes no solo, aliado às melhores condições climáticas neste período (temperatura mais elevada e maior incidência de chuvas). Andrade Junior et al. (2005) observaram, aos 42 DAT, sob irrigação por aspersão, peso máximo de massa fresca para a cultivar Elisa, de 423 g (casca de café) e o mínimo de 178 g por planta (solo sem cobertura). Gomes et al. (2005) mostraram que, com as doses de $\mathrm{CO}_{2}\left(0,52,155\right.$ e $\left.310 \mathrm{~kg} \mathrm{ha}^{-1}\right)$, aplicadas via água, utilizando a irrigação por gotejamento, para a alface Elisa não houve interferência sobre a massa fresca obtendo-se o valor máximo de $240 \mathrm{~g}_{\text {planta }}{ }^{-1}$.

Massa seca total: Constatou-se, no $1^{\circ}$ ciclo, diferença significativa entre a água residuária e água do depósito, aplicadas em aspersão, aos 25 e 45 DAT (Tabela 6). As duas qualidades de água diferiram também no gotejamento subterrâneo aos 25, 33 e 45 DAT. Quanto ao gotejamento superficial, a massa seca total diferiu apenas aos 45 DAT. Com água residuária, a aspersão diferiu do gotejamento subterrâneo e superficial aos 45 DAT, enquanto aos 25 e 33 DAT os três sistemas de irrigação diferiram entre si.

No $2^{\circ}$ ciclo, porém, a diferença foi significativa entre a água residuária e a do depósito, no gotejamento subterrâneo e no superficial, aos 41 DAT, enquanto aos 33 DAT diferiu somente no gotejamento superficial. Também aos 33 DAT, a aspersão e o gotejamento subterrâneo diferiram do gotejamento superficial no qual se utilizou água residuária.

$\mathrm{O}$ acúmulo de massa seca foi pequeno na fase inicial de crescimento (até 25 DAT) em ambos os ciclos da cultura. A partir desta data até os 40 e 41 DAT, nos $1^{\circ}$ e $2^{\circ}$ ciclos, respectivamente, houve ganho acentuado de massa seca total. A partir dos 40 DAT no $1^{\circ}$ ciclo, a taxa de ganho de massa seca foi praticamente constante em relação ao período anterior, com exceção dos tratamentos AR e GSbR, que mostraram menores ganhos de massa seca em relação ao período anterior. Este mesmo comportamento foi verificado no $2^{\circ}$ ciclo, mas apenas no tratamento AD, que apresentou menor ganho de massa seca.
Os maiores valores de massa seca total foram obtidos no $2^{\circ}$ ciclo da cultura, oscilando entre 11,52 (AR) e 13,30 g (GSpR) por planta nos tratamentos com água residuária tratada e entre 9,42 (GSbD) a 9,98 g (GSpD) por planta para a água do depósito. É conveniente lembrar que a aspersão com água residuária, embora contenha nutriente em maior proporção que os tratamentos em que a água é do depósito, indicou queda acentuada no crescimento da alface, desde o início do ciclo devido, provavelmente, às modificações nas propriedades químicas do solo, como a compactação, decorrente da elevada umidade do solo na ocasião em que os canteiros foram confeccionados.

Área foliar: Na amostragem aos 33 e 45 DAT no $1^{\circ}$ ciclo observou-se diferença significativa das plantas irrigadas por aspersão com água residuária e do depósito superficial; já no gotejamento subterrâneo, a diferença de área foliar entre a água residuária e a água do depósito, foi constatada a partir dos 25 DAT até o final do ciclo mostrando que, neste sistema de irrigação comparado ao gotejamento superficial, o uso de água residuária aumentou o ganho de área foliar, principalmente do início do ciclo até 40 DAT. A partir dos 25 DAT até o final, ocorreu diferença significativa entre as plantas do gotejamento subterrâneo e a aspersão utilizando água residuária, embora aos 33 e 45 DAT o gotejamento superficial tenha diferido da aspersão, com maiores ganhos de área foliar no gotejamento (Tabela 6).

Por outro lado, no $2^{\circ}$ ciclo, constatou-se diferença significativa de área foliar, entre os tratamentos com água residuária e água do depósito, nas datas de amostragem aos 25, 33 e 41 DAT, tanto no gotejamento subterrâneo como no superficial. Verificou-se diminuição da área foliar na aspersão na última data de amostragem, diferindo do gotejamento subterrâneo e superficial quando do uso de água residuária, fato este associado à não homogeneidade da parcela de que foram retiradas as amostras.

Para melhor ganho pelo agricultor, do ponto de vista comercial, é aconselhável que a colheita da alface seja realizada quando as plantas atingirem a área foliar máxima (Hamada 1995). Neste sentido, se observou, no experimento, que em todos os tratamentos e em ambos os ciclos as plantas ainda se estavam desenvolvendo, o que se supõe ser possível esperar mais tempo melhorando, desta forma, a área foliar e os demais parâmetros de crescimento.

Eficiência do uso de água: A Tabela 7 apresenta os valores de produtividade (massa fresca total) e eficiência do uso de água nos $1^{\circ}$ e $2^{\circ}$ ciclos, em função da lâmina total de água aplicada. A eficiência do uso da água foi definida como a produtividade $\left(\mathrm{g} \mathrm{m}^{-2}\right)$ por unidade de lâmina de água aplicada (mm), calculada desconsiderando-se a precipitação efetiva que ocorreu durante os dois ciclos da cultura.

Vê-se, nitidamente, que os maiores valores de produtividade média no $1^{\circ}$ ciclo foram obtidos com os tratamentos nos quais se utilizou água residuária e irrigação por gotejamento subterrâneo, porém a maior eficiência do uso de água foi obtida no tratamento GSpR. Nos tratamentos com água do depósito de fonte superficial, obteve-se a maior produção no gotejamento superficial, seguido do gotejamento subterrâneo, embora a maior eficiência do uso de água haja sido obtida 
Tabela 7. Lâmina de irrigação, massa fresca total $(\mathrm{Pr})$ e eficiência do uso de água para os seis tratamentos, no final dos $1^{\circ}$ e $2^{\circ}$ ciclos da cultura

\begin{tabular}{|c|c|c|c|c|c|c|}
\hline \multirow[b]{2}{*}{ Tratamento* } & \multicolumn{3}{|c|}{$1^{0}$ ciclo } & \multicolumn{3}{|c|}{$2^{0}$ ciclo } \\
\hline & $\begin{array}{c}\mathrm{LA} \\
(\mathrm{mm})\end{array}$ & $\begin{array}{c}\mathrm{Pr} \\
\left(\mathrm{g} \mathrm{m}^{-2}\right)\end{array}$ & $\underset{\left(g L^{-1}\right)}{E A}$ & $\begin{array}{c}\mathrm{LA} \\
(\mathrm{mm})\end{array}$ & $\underset{\left(\mathrm{g} \mathrm{m}^{-2}\right)}{\mathrm{Pr}}$ & $\begin{array}{c}E A \\
\left(\mathrm{~g} \mathrm{~L}^{-1}\right)\end{array}$ \\
\hline$A R$ & 79,5 & 2472,5 & 31,1 & 142,7 & 4238,2 & 29,7 \\
\hline GSpR & 72,1 & 3934,6 & 54,5 & 127,2 & 4528,5 & 35,6 \\
\hline GSbR & 75,8 & 4055,6 & 53,5 & 134,5 & 4792,2 & 35,6 \\
\hline GSpD & 73,0 & 3290,0 & 45,1 & 127,9 & 3274,4 & 25,6 \\
\hline GSbD & 74,7 & 2848,0 & 38,1 & 131,2 & 3021,2 & 23,0 \\
\hline$A D$ & 80,6 & 2383,3 & 29,6 & 143,2 & 3751,6 & 26,2 \\
\hline
\end{tabular}

* AR: aspersão com água residuária; AD: aspersão com água do depósito; GSbR: gotejamento subterrâneo com água residuária; GSbD: gotejamento subterrâneo com água do depósito; GSpR gotejamento superficial com água residuária e GSpD: gotejamento superficial com água do depósito. EA: eficiência do uso de água; LA: lâmina aplicada e Pr: Produtividade

no tratamento GSpD. O uso de informações de produtividade e eficiência do uso da água são importantes para a análise econômica da produção e, manejo da irrigação e ainda auxilia na economia do uso da água.

No $2^{\circ}$ ciclo os valores médios de produção foram superiores aos obtidos no $1^{\circ}$ ciclo, com exceção do tratamento GSpD. Os tratamentos GSbR e GSpR apresentaram maiores valores médios de produção que a AR, a exemplo do que ocorreu no $1^{\circ}$ ciclo, porém com diferenças menos acentuadas. A eficiência do uso de água foi praticamente a mesma nos tratamentos GSbR e GSpR e menor na AR, enquanto nos tratamentos com água do depósito a maior eficiência do uso de água foi na $\mathrm{AD}$. A eficiência de uso de água no $2^{\circ}$ ciclo é considerada baixa em virtude, possivelmente, da incidência de chuvas ocorridas no período sendo que as mesmas não foram consideradas no cálculo deste índice e a lâmina de água aplicada em cada irrigação foi sempre relacionada a um valor de evapotranspiração de referência (ETo).

A diferença nos valores de produção entre a aspersão e o gotejamento subterrâneo e superficial no $1^{\circ}$ ciclo, foi de 64 e 59\%, respectivamente, utilizando-se água residuária; esses valores são inferiores aos encontrados por Bureau et al. (1987), notando-se diferença significativa, quando da utilização de água residuária doméstica e água de um depósito superficial, aplicadas por gotejamento, na produção de algumas culturas, entre elas a alface. Araújo et al. (1999) empregando água poluída de um córrego na irrigação da alface em colunas de PVC rígido de 200 mm de diâmetro e 750 mm de comprimento, constataram que os nutrientes e a matéria orgânica favoreceram a fertilização do solo, o que melhorou significativamente a produtividade da cultura.

A produção da alface no final do $1^{\circ}$ ciclo com água residuária apresentou diferença significativa, entre a aspersão e os sistemas de gotejamento subterrâneo e superficial. Os três sistemas de irrigação com que se utilizou água do depósito, também diferiram entre si; notou-se, no $2^{\circ}$ ciclo, diferença significativa entre o tratamento GSbR e GSbD e entre o GSpR e GSpD.

A produtividade versus lâmina de irrigação não mostrou linearidade entre os tratamentos; nota-se, entretanto, que a qualidade da água influenciou na produtividade da alface ocorrendo, assim, maior produtividade nos tratamentos irrigados com água residuária em relação aos tratamentos com água do depósito, principalmente no gotejamento subterrâneo e superficial, cujo fato se deve, sobretudo à disponibilidade de nutrientes, como nitrogênio, fósforo e potássio na água residuária, os quais são mais bem aproveitados quando do uso do gotejamento. Em todos os tratamentos a produtividade foi inferior aos obtidos por Juchen (2000), com a cultivar "Americana”, nas condições da região de Cascavel, PR, utilizando a irrigação por gotejamento para aplicação de água residuária de laticínio e frigorífico, o que era previsto, uma vez que esta cultivar apresenta plantas de maior porte. Hamada (1995), verificou que a menor lâmina de água aplicada foi a que apresentou maior eficiência no uso de água.

\section{Qualidade da alface}

Observou-se, durante o $1^{\circ}$ ciclo, que nos tratamentos AR e $\mathrm{AD}$ a maior porcentagem, $60,0 \%$ e $63,3 \%$ do total de plantas, respectivamente, esteve na classe 10 ; no $2^{\circ}$ ciclo, as classes foram alteradas, isto é, para o tratamento AR a maior porcentagem das plantas ficou nas classes 20 e 25, com valores de 43,3 e $46,7 \%$, respectivamente, enquanto no tratamento AD, 50,0\% se concentraram na classe 20 e 30,0\% na classe 25 (Tabela 8).

Tabela 8. Análise da classificação da alface em porcentagem, segundo definição da CEAGESP para os dois ciclos da cultura e para os seis tratamentos

\begin{tabular}{|c|c|c|c|c|c|c|c|c|}
\hline \multicolumn{3}{|c|}{ Classificação } & \multicolumn{6}{|c|}{ Tratamentos $^{1}$} \\
\hline \multirow{2}{*}{$\begin{array}{l}\text { Limite de } \\
\text { peso inferior } \\
\text { (g) }\end{array}$} & \multirow[t]{2}{*}{ Classe } & \multirow{2}{*}{$\begin{array}{l}\text { Limite de } \\
\text { peso superior } \\
\text { (g) }\end{array}$} & AR & GSbR & GSpR & $A D$ & GSbD & GSpD \\
\hline & & & & \multicolumn{5}{|c|}{ orcentagem de plantas por classe } \\
\hline \multicolumn{9}{|c|}{$1^{0}$ ciclo } \\
\hline$\geq 100$ & 10 & $<150$ & 60,0 & - & - & 63,3 & 33,3 & 3,3 \\
\hline$\geq 150$ & 15 & $<200$ & 23,3 & 23,3 & 20,0 & 26,7 & 40,0 & 50,0 \\
\hline$\geq 200$ & 20 & $<250$ & 10,0 & 26,7 & 33,3 & 10,0 & 16,7 & 30,0 \\
\hline$\geq 250$ & 25 & $<300$ & 6,7 & 26,7 & 33,3 & - & 10,0 & 10,0 \\
\hline$\geq 300$ & 30 & $<350$ & - & 16,6 & 13,4 & - & - & 6,7 \\
\hline$\geq 350$ & 35 & $<400$ & - & 6,7 & - & - & - & - \\
\hline \multicolumn{9}{|c|}{$2^{0}$ ciclo } \\
\hline$\geq 150$ & 15 & $<200$ & - & - & - & 16,7 & 76,7 & 56,7 \\
\hline$\geq 200$ & 20 & $<250$ & 43,3 & 23,3 & 40,0 & 50,0 & 23,3 & 33,3 \\
\hline$\geq 250$ & 25 & $<300$ & 46,7 & 36,7 & 26,7 & 30,0 & - & 10,0 \\
\hline$\geq 300$ & 30 & $<350$ & 10,0 & 23,3 & 13,3 & 3,3 & - & - \\
\hline$\geq 350$ & 35 & $<400$ & - & 10,0 & 20,0 & - & - & - \\
\hline$\geq 400$ & 40 & $<450$ & - & 6,7 & - & - & - & - \\
\hline
\end{tabular}

${ }^{1}$ Análise de 30 plantas por tratamento; AR: aspersão com água residuária; AD: aspersão com água do depósito; GSbR: gotejamento subterrâneo com água residuária; GSbD: gotejamento subterrâneo com água do depósito; GSpR: gotejamento superficial com água residuária e GSpD: gotejamento superficial com água do depósito

Analisando-se o tratamento GSbR no $1^{\circ}$ ciclo, verificouse que $26,7 \%$ das plantas de alface se encontravam na classe 20 e o mesmo índice na classe 25 , somando 53,4\%, enquanto no tratamento GSbD $73,3 \%$ se concentraram nas classes de 10 e 15; já no $2^{\circ}$ ciclo, no GSbR 83,3\% ficaram entre as classes de 20 a 30 com maior parte das plantas na classe 25 , enquanto no tratamento GSbD $76,7 \%$ se situavam na classe 15 e o restante na classe 20. Quanto ao tratamento GSpR, no $1^{\circ}$ ciclo as classes que apresentavam maior porcentagem de plantas foram as de 20 a 25 com total de 
$66,9 \%$, enquanto no tratamento GSpD $50,0 \%$ do total de plantas se encontraram nas classes 15 e 30,0\% na classe 20, totalizando $80,0 \%$.

Vê-se que, no $1^{\circ}$ ciclo, os tratamentos GSbR e GSpD foram os que mostraram maior variação entre as classes cujas plantas foram distribuídas em cinco diferentes classes; no entanto, a maior proporção de plantas em cada tratamento ficou concentrada em classes diferentes, isto é, no tratamento GSbR a maior parte das plantas se concentrou em classes de maior peso, indicando maior produção de massa fresca; no $2^{\circ}$ ciclo, o tratamento GSbR apresentou distribuição em maior número de classes; por outro lado, o tratamento GSbD foi o que indicou menor número de classes, distribuindo-as em apenas duas enquadradas, no entanto, em classes de menor peso em relação aos demais tratamentos, indicando menor produção de massa fresca; no $1^{\circ}$ ciclo, o tratamento AD apresentou distribuição em menor número de classes concentrando-se em apenas 3 classes.

Considerando-se as especificações da CEAGESP (2001), que recomenda uma mistura de $10 \%$ de classes em uma embalagem, desde que seja imediatamente superior ou inferior ou $20 \%$ de embalagens no lote fora das especificações observa-se, pelos resultados, que a alface produzida caso fosse toda enviada para comercialização, não atenderia às especificações, o que exige que se faça uma seleção, separando-as em mais de um lote.

Para a cultivar de alface Elisa, a classe mais freqüentemente encontrada nos pontos de venda ao consumidor, é a 20; vê-se então, que no $2^{\circ}$ ciclo a maior porcentagem de plantas estava nesta classe ou próximo, em todos os tratamentos, ao contrário no $1^{\circ}$ ciclo, que apresentou maior porcentagem de plantas na classe 15 ou inferior a esta, especialmente nos tratamentos em que se usou água do depósito (Tabela 8); no entanto, observa-se que o desenvolvimento da alface está diretamente relacionada às condições de cultivo, sistema de irrigação, qualidade da água, fertilidade do solo, épocas de cultivo, condições ambientais, dentre outros fatores. Considerando alguns autores (Gomes et al., 2005; Andrade Júnior et al., 2005; Dantas \& Escobedo, 1998), constata-se que para a alface cultivar Elisa as classes entre 15 e 40 são as mais encontradas.

\section{CONCLUSÕES}

1. Os maiores valores de massa seca, massa fresca e área foliar, foram obtidos nos tratamentos com água residuária, mas a altura da planta e o número de folhas foram pouco influenciados pelo uso de água residuária, em todas as datas de amostragem.

2. O uso de água residuária demonstrou ser uma fonte de nutrientes para as plantas, interferindo principalmente na formação de massa fresca e, por conseqüência, na área foliar.

3. A produtividade da alface nos dois ciclos foi mais elevada nos sistemas de irrigação por gotejamento subterrâneo e superficial utilizando água residuária, quando comparada com o uso de água do depósito.
4. A maior eficiência no uso de água foi obtida nos sistemas de irrigação por gotejamento subterrâneo e superficial em que se utilizou água residuária, em ambos os ciclos da cultura.

5. A maior porcentagem de plantas com água residuária e do depósito, se apresentava nas classes 20 e 25 e 15 e 20, respectivamente, em ambos os ciclos da cultura.

\section{AgRADECIMENTOS}

À Fundação de Amparo à Pesquisa do Estado de São Paulo, pelo auxílio concedido, e à Faculdade de Engenharia Agrícola, UNICAMP.

\section{LITERATURA CITADA}

Andrade Júnior, V. C.; Yuri, J. E.; Nunes, U. R.; Pimenta, F. L.; Matos, C. S. M.; Florio, F. C. A.; Madeira, D. M. Emprego de tipos de cobertura de canteiro no cultivo da alface. Horticultura Brasileira, Brasília, v.23, n.4, p.899-903, 2005.

APHA - American Public Health Association. Standard methods for examination of water and wastewater. 19. ed. Washinton: D.C. APHA, 1995. 1193p.

Araújo, A. L.; König, A.; Milanêz, J. G.; Ceballos, B. S. O. Reúso indireto de esgotos na irrigação de colunas experimentais de solo cultivadas com alface (Lactuca Sativa L.). In: Congresso Brasileiro de Engenharia Sanitária e Ambiental, 20, 1999, Rio de Janeiro. Anais... Rio de Janeiro: ABES, 1999. I-119.

Armon, R.; Gold, D.; Brodsky, M.; Oron. G. Surface and subsurface irrigation with effluents of different qualities and presence of Cryptosporidium Oocysts in soil and on crops. Water Science and Technology. Oxford, v.46, n.3, p.115-112, 2002.

Ayers, R. S.; Westcot, D. W. A qualidade da água na agricultura. 2.ed. Campina Grande: UFPB, 1991. 218p. Estudos da FAO: Irrigação e Drenagem, 29 Revisado 1.

Barros, A. J. M.; Ceballos, B. S. O.; König, A.; Gheyi, H. R. Avaliação sanitária e físico-química das águas para irrigação de hortaliças no agreste e brejo paraibanos. Revista Brasileira de Engenharia Agrícola e Ambiental, Campina Grande, v.3, n.3, p.355-360, 1999.

Biscaro, G. A.; Trigueira, M.; Grassi Filho, H.; Cruz, R. L. Diferentes níveis de adubação para a cultura da alface (Lactuca sativa L.) cultivada em vasos e irrigada com água residuária - segundo ciclo. In: Congresso Brasileiro de Engenharia Agrícola, 31, 2002, Salvador. Anais... Salvador: UFBA, 2002. CD-Rom.

Boink, A.; Speijers, G. Health effect of nitrates and nitrites, a review. Acta Horticultura, Cairo, n.563, p. 29-36, 2001.

Brasil. Resolução CONAMA, Conselho Nacional do Meio Ambiente n. 357 de 17 de março de 2005. Brasília: Diário Oficial da República Federativa do Brasil, 2005. 23p.

Bureau, R. G.; Sheih, B.; Cort, R. P.; Cooper, R. C.; Ririe, D. Reclaimed water for irrigation of vegetables eaten raw. California Agriculture, California, v.41, n.7-8, p.4-7, 1987.

Camargo, L. S. As hortaliças e seu cultivo. 2.ed. Campinas: Fundação Cargill, 1984. 448p. 
CEAGESP - Companhia de Entrepostos e Armazéns Gerais de São Paulo. Programa paulista para a melhoria dos padrões comerciais e embalagens de hortigranjeiros. Classificação de alface. Programa de adesão voluntária, São Paulo, 2001.

CEASA/Campinas. Padronização/Alface. http://www.ceasacampinas.com.br. 05 Abr. 2006.

Crook, J. Quality criteria for reclaimed water. Water Science Technology. Oxford, v.24, n.9, p.109-121, 1991.

Dantas, T. D.; Escobedo, J. F. Índices morfo-fisiológicos e rendimento da alface (Lactuca sativa L.) em ambiente natural e protegido. Revista Brasileira de Engenharia Agrícola e Ambiental, Campina Grande, v.2, p.27-31, 1998.

EPVA - Environmental Protection Authority of Victoria. Guidelines for wastewater irrigation, Melbourne: EPVA, 1991. 60p. (Publication, 168).

Feigin, A.; Ravina, I.; Shalhevet, J. Irrigation with treated sewage effluent: management for environmental protection. Berlin: Springer-Verlag, 1991, 233p.

Friedler, E.; Juniaco, M. Tratament and storage of wastewater for agricultural irrigation. Agritech/1996. Tel-Aviv: Agronitech Technology Ltda., 1996, 7p.

Gomes, T. M.; Botrel, T. A.; Modolo, V. A.; Oliveira, R. F. Aplicação de $\mathrm{CO}_{2}$ via água de irrigação na cultura da alface. Horticultura Brasileira, Brasília, v.23, n.2. p.316319, 2005.

Hach Company. DBOTrak Instrument Manual. 3.ed. Loveland: Hach Company, 1997. 64p.

Hamada, E. Desenvolvimento e produtividade da alface submetida a diferentes lâminas de água através da irrigação por gotejamento. Pesquisa Agropecuária Brasileira. Brasilia, v.9, n.30, p.1201-1209, 1995.

Hunt, R. Plant growth analysis. London: Edward Arnold, 1978. 69p.

Jucken, C. R. Avaliação do reúso de efluentes tratados das agroindústrias de leite e carne sobre a produção da cultura da alface (Lactuca sativa L.) fertirrigada. Cascavel: FEA/UNIOESTE, 2000, 73p. Dissertação Mestrado

Kirkam, M. B. Problems of using wastewater on vegetable crops. HortScience, Alexandria, v.21, n.1, p.24-27. 1986.
Lisbão, R. S.; Nagai, H.; Trani, P. E. Alface. In: Instruções agrícolas para o estado de São Paulo. 5.ed. Revisada e atualizada. Boletim 200. Campinas: Instituto Agronômico de Campinas, p.11-12, 1990. 233p.

Medeiros, S. S.; Soares, A. A.; Ferreira, P. A.; Neves, J. C. L.; Matos, A. T.; Souza, J. A. A. Utilização de água residuária de origem doméstica na agricultura: Estudo das alterações químicas do solo. Revista Brasileira de Engenharia Agrícola e Ambiental, Campina Grande, v.9, n.4, p.603-612, 2005.

Miranda, T. L. G. Reúso de efluente de esgoto doméstico na irrigação de alface (Lactuca sativa L.). Porto Alegre: Instituto de Pesquisas Hidráulicas/UFRGS, 1995, 109p. Dissertação Mestrado

Osburn, R. C.; Burkhead, C. E. Irrigating vegetables with reclaimed wastewater. Water Environment \& Technology, Alexandria, v.4, n.8, p.38-42. 1992.

Paganini, W. S. Disposição de esgotos no solo: escoamento à superfície. São Paulo: AESABESP, 1997, 232p.

Pereira, A. R.; Machado, E. C. Análise quantitativa de crescimento de comunidades vegetais. Campinas: Instituto Agronômico/ Fundação IAC, 1987. 33p. Boletim Técnico 114.

Silva, T. C.; Noronha, E. O.; Hespanhol, R. A. M. O cinturão verde no município de Mogi das Cruzes, SP. http://www.igeo.uerj.br/VICBG-2004/Eixo1/e1_cont01.htm. 28 Mar. 2006.

Trani, P. E. Hortaliças folhosas e condimentos. In: Pereira, M. E.; Cruz, M. C. P.; van Raij, B.; Abreu, C. A. (ed.) Micronutrientes e elementos tóxicos na agricultura. Jaboticabal: CNPq/FAPESP/POTAFOS, 2001, p.293-510.

Trani, P. E.; Carrijo, O. A. Fertirrigação em hortaliças. Campinas: Instituto Agronômico, 58 p. 2004, Boletim Técnico IAC, 196

Trani, P. E.; van Raij, B. Hortaliças. Boletim Técnico do Instituto Agronômico, 2.ed. Campinas, n.100, p.30-36. 1997.

Valentim, M. A. A. Desempenho de leitos cultivados ("constructed wetland”) para tratamento de esgoto: contribuições para concepção e operação. Campinas: FEAGRI/UNICAMP, 2003, 210p. Tese Doutorado

WHO - World Helth Organization. Health guidelines for the use of wasterwater in agriculture and aquaculture. Geneva: WHO. 1989. 72p. Technical Report Serie, n.778. 